\title{
A Modeling and Observational Framework for Diagnosing Local Land-Atmosphere Coupling on Diurnal Time Scales
}

\author{
Joseph A. Santanello, Jr. ${ }^{1}$, Christa D. Peters-Lidard ${ }^{1}$, Sujay V. Kumar ${ }^{1,2}$, \\ Charles Alonge ${ }^{1,3}$, Wei-Kuo Tao ${ }^{4}$ \\ ${ }^{1}$ NASA-GSFC Hydrological Sciences Branch, Greenbelt, MD \\ ${ }^{2}$ Goddard Earth Sciences and Technology Center, UMBC, Baltimore, MD \\ ${ }^{3}$ Science Applications International Corporation, Beltsville, MD \\ ${ }^{4}$ NASA-GSFC Mesoscale Processes Branch, Greenbelt, MD
}

Submitted to Journal of Hydrometeorology

Revised January 2009 


\begin{abstract}
Land-atmosphere interactions play a critical role in determining the diurnal evolution of both planetary boundary layer $(\mathrm{PBL})$ and land surface temperature and moisture states. The degree of coupling between the land surface and PBL in numerical weather prediction and climate models remains largely unexplored and undiagnosed due to the complex interactions and feedbacks present across a range of scales. Further, uncoupled systems or experiments (e.g., the Project for Intercomparison of Land Parameterization Schemes, PILPS) may lead to inaccurate water and energy cycle process understanding by neglecting feedback processes such as PBL-top entrainment. In this study, a framework for diagnosing local land-atmosphere coupling is presented using a coupled mesoscale model with a suite of PBL and land surface model (LSM) options along with observations during field experiments in the U. S. Southern Great Plains. Specifically, the Weather Research and Forecasting (WRF) model has been coupled to the Land Information System (LIS), which provides a flexible and high-resolution representation and initialization of land surface physics and states. Within this framework, the coupling established by each pairing of the available PBL schemes in WRF with the LSMs in LIS is evaluated in terms of the diurnal temperature and humidity evolution in the mixed layer. The co-evolution of these variables and the convective PBL is sensitive to and, in fact, integrative of the dominant processes that govern the PBL budget, which are synthesized through the use of mixing diagrams. Results show how the sensitivity of land-atmosphere interactions to the specific choice of PBL scheme and LSM varies across surface moisture regimes and can be quantified and evaluated against observations. As such, this methodology provides a potential pathway to study factors controlling local land-atmosphere coupling (LoCo) using the LIS-WRF system, which will serve as a testbed for future experiments to evaluate coupling diagnostics within the community.
\end{abstract}




\section{Introduction}

Land-atmosphere (L-A) interactions and coupling remain weak links in current observational and modeling approaches to understanding and predicting the Earth-Atmosphere system. The degree to which the land impacts the atmosphere (and vice-versa) is difficult to quantify given the disparate resolutions and complexities of land surface and atmospheric models and lack of comprehensive observations at the process level (Betts et al. 1996; Angevine 1999; Entekhabi et al. 1999; Betts 2000; Cheng and Steenburgh 2005; Gu et al. 2006). However, the convective planetary boundary layer (PBL) serves as a short-term memory of land surface processes (through the integration of regional surface fluxes on diurnal scales), and is therefore diagnostic of the surface energy balance. Further, the equilibrium established between land surface and mixed layer fluxes and states in a growing PBL is a function of the degree of coupling and the impact of feedbacks within the L-A system (Pan and Mahrt 1987; Oke 1987;

Stull 1988; Diak 1990; Garratt 1992; Dolman et al. 1997; Peters-Lidard and Davis 2000; Cleugh et al. 2004; Betts and Viterbo 2005). As such, knowledge of temperature and moisture evolution in the PBL can be instrumental in estimating surface fluxes and properties across regional scales as well as quantifying and improving L-A representations in coupled models.

Recent efforts to better understand and quantify the nature and processes involved in L-A interactions have focused on advancing the theory and formulation of their complex behavior and feedbacks (Sorbjan 1995; Steeneveld et al. 2006), deriving and exploiting relationships among observed L-A properties (Eltahir 1998; Santanello et al. 2005, 2007), and assessing these interactions using coupled models (Margulis and Entekhabi 2001; Barros and Hwu 2002; Ek and Holtslag 2004; Santanello et al. 2007). While progress has been made in identifying individual processes and feedback loops for a particular location or model, a comprehensive approach to 
diagnosing the full nature of L-A coupling that can be applied to models and evaluated against observations has yet to be developed. The need for such a framework will only become more critical to ensure that advances in measurement technologies such as satellite remote sensing of the land surface and PBL are properly incorporated into L-A studies and models (e.g. data assimilation).

A relatively simple but untested approach by Betts (1992) to quantifying heat and moisture budgets in the PBL is based upon a vector representation of the diurnal evolution of temperature and humidity. Application of this 'mixing diagram' theory to models and observations would offer the ability to perform a robust evaluation of L-A interactions with minimal inputs due to the integrative nature of the mixed layer on diurnal time scales. Ideally, this approach should be tested using a coupled, high-resolution, mesoscale model with flexible land surface and PBL schemes, thereby allowing the variation in L-A coupling among different formulations versus that observed to be evaluated.

With these issues in mind, this paper defines a methodology to quantify local L-A coupling and the various components and feedbacks therein. Section 2 presents an overview of recent progress in L-A research and the complexities of the governing processes and feedbacks, including the growing need for studies of L-A coupling at the local (regional) scale, and describes the mixing diagram approach that is adopted and extended in this study. The coupled regional model, land surface models, and PBL schemes used in the experiments are highlighted in Section 3 along with detailed information on the sites, case studies, and associated observations. Results and analyses of the mixing diagram approach applied to these experiments are presented in Section 4, followed by a discussion of the greater applicability and limitations of 
this methodology in Section 5. Finally, Section 6 presents the conclusions and summary of current and future work related to L-A research.

\section{Background}

\section{a. Motivation for Studying L-A Coupling}

The need for improved understanding, estimation, and prediction of L-A interactions and feedbacks has been growing significantly over the last decade (Jacobs and DeBruin 1992; Entekhabi and Brubaker 1995; Kim and Entekhabi 1998; Entekhabi et al. 1999; Liu et al. 2003, 2004, 2005; Medeiros et al. 2005; Dirmeyer et al. 2004). During this time, offline (uncoupled) land surface models (LSMs) have grown in complexity and diversity, while the applicability of offline model evaluations, such as those performed during the Project for Intercomparison of Land-surface Parameterization Schemes (PILPS) experiments (Henderson-Sellers et al. 1993), may be severely limited to the omission of L-A interactions and feedbacks (e.g. Liu et al. 2003, 2004, 2005). At the same time, LSMs coupled to atmospheric models are often highly tuned to each other without regard for the degree and accuracy of coupling between the L-A schemes or the impact of feedbacks. In both instances, our ability to diagnose and quantify these interactions is lacking, and needs to be improved by evaluating the best available PBL and land surface data in the context of the mixed layer evolution and equilibrium established through their interactions and feedbacks, and how this compares to what is simulated in our models.

The Global Land/Atmosphere System Study (GLASS), part of the Global Energy and Water Cycle Experiment (GEWEX; www.gewex.org) program, was designed to serve as an interface between the land-surface community and efforts to observe, understand, and model the hydrological cycle and energy fluxes in the Earth-Atmosphere system. GLASS is composed of four actions that support the intercomparison and advancement of a) large scale offline, b) large 
scale coupled, c) local scale offline, and d) local scale coupled models. Currently, each of these is being addressed through organized, community-wide modeling studies [a) Global Soil Wetness Project (GSWP-2; Dirmeyer et al. 1999), b) Global Land Atmosphere Coupling Experiment (GLACE; Koster et al. 2002), and c) PILPS], with the exception of local scale coupled studies (hereafter referred to as 'LoCo'). There have been community workshops and tentative implementation plans (e.g. van den Hurk et al. 2005) for a LoCo initiative, but to date an organized effort and lead for LoCo is still under development.

Recent GLASS-related studies have highlighted the importance and difficulties in understanding the complexity and impacts of L-A interactions. For example, the GLACE study, while looking from a global perspective on non-local impacts of the land on the atmosphere and vice-versa, show that there are regions of highly coupled L-A environments that impact precipitation patterns and cycling (Koster et al. 2004; Lawrence and Slingo 2005). These hotspots are therefore likely to be of interest to LoCo. Similarly, the GEWEX Atmospheric Boundary Layer Study (GABLS) community has attempted to isolate and intercompare an array of PBL schemes (i.e. single-column models) while controlling atmospheric and land surface boundary forcing, but in the process has shown the importance of accounting for a variable land surface that is fully interactive with the PBL (Holtslag et al. 2007). As a result, the GLACE and GABLS communities also have a vested interest in a LoCo action.

From outside the GEWEX community, there have been a host of studies focused on a variety of individual L-A processes and feedbacks that call for further study of LoCo in a comprehensive and quantitative manner (e.g. Brubaker and Entekhabi 1996; Kim and Entekhabi 1998; Berbery et al. 2003; Findell and Eltahir 2003ab). For example, Cheng and Steenburgh (2005) and Gu et al. (2006) demonstrate that the large variability of coupling in models and the 
lack of quantitative understanding of the relevant processes need to be addressed including both direct and indirect (i.e. feedback) effects. Betts (2000) and Betts and Viterbo (2005) show that the L-A coupling is also critical in global model reanalysis data, but also stress that the critical processes and relationships that determine model evolution and equilibrium lie on the local scale and lack sufficient understanding and representation in models of all scales.

Inherent in the ability to accurately simulate L-A interactions in coupled models is the engineering of the coupling itself in terms of model design and variable passing from land surface to surface layer and PBL schemes, and vice-versa. Polcher et al. (1998) and Best et al. (2004) have proposed a generalized coupling design in this regard, but highlight the complexities involved in time-stepping of the coupled variables, and in specifying the blending height (i.e. tiling; Molod et al. 2004) and surface layer (Chen et al. 1997a) within each model. Overall, coupling design remains a largely model-dependent decision based on ease of implementation, rather than that which provides the most accurate representation of the L-A processes.

Because we do not yet know the full nature of L-A coupling in models and acknowledge that the physics within LSMs is incomplete in many respects, there have been numerous efforts to calibrate model parameters to improve simulations. For example, Liu et al. $(2003,2004$, and 2005) demonstrated the ability to optimize large sets of L-A parameters, but that there are large differences in the offline and coupled cases. Unfortunately, as shown by Hogue et al. (2005), such extensive parameter calibrations are also completely model and site-dependent, and as a result do not tell us anything about the true nature of L-A coupling, its quantification, or how accurately it is represented in each model.

Another important motivation for further understanding L-A coupling lies in its direct impact on data assimilation of PBL and land surface states. There have been numerous efforts to 
assimilate screen-level observations in offline (Rhodin et al. 1999; Hess 2001), single-column (Hacker and Snyder 2005; Hacker and Rostkier-Edelstein 2007), and fully coupled (Seuffert et al. 2004) models. However, a great deal of testing of land data assimilation of soil moisture, surface temperature, and snow has been performed for offline models (Rodell and Houser 2004; Reichle et al. 2007; Bosilovich et al. 2007), which lack L-A interactions and feedbacks that otherwise would impact the assimilation results in coupled mode. As efforts to assimilate new remote sensing data increase along with the complexity of assimilation techniques, the manner in which the land and atmosphere are coupled as well as the strength of feedbacks becomes critical to the process.

Recent attempts to further understand and quantify L-A interactions have identified key properties, relationships, and feedback mechanisms using targeted modeling and observational approaches. Ek and Holtslag (2004) have derived a formulation for relative humidity tendency at the top of the PBL that aids in identifying moistening and drying regimes, and incorporates the full set of L-A processes (and inherent feedbacks) governing PBL evolution. Similarly, Barros and Hwu (2002) investigated the L-A interactions that determine summer rainfall patterns using a mesoscale model. While their approach is slightly broader than that of Ek and Holtslag in spatial (synoptic) and temporal (daily-weekly) scales, they identify different timescales of feedbacks, as evidenced in the relationship of near-surface relative humidity to surface Bowen ratio, which represent moist and dry dominated processes. From a more local perspective, Santanello et al. $(2005,2007)$ demonstrate the utility of readily observable properties of the PBL and land surface (e.g. PBL height, diurnal 2m-temperature change, soil moisture, and atmospheric stability) and the strong relationships therein. Their results show that these properties are integrative of L-A interactions and feedbacks, and have since been supported by 
studies using a coupled regional model (Desai et al. 2006; Reen et al. 2006) that highlight the importance of LoCo in atmospheric modeling.

\section{b. Mixing Diagram Approach}

\section{1) METHODOLOGY AND APPLICABILITY}

The previous section details the recent progress, difficulties, and need for further research to quantify LoCo in observations and models. It is apparent from these studies that in order for a robust methodology to diagnose coupling to be effective and useful to the community, it must be comprehensive and integrative of L-A processes and feedbacks; while at the same time able to be implemented using easily observed and understood properties of the system.

An approach that may satisfy these requirements for diurnal time scales is the concept of vector representation of heat and moisture (energy) budgets, as introduced by Betts $(1984,1992)$ in the form of 'mixing diagrams'. This conservative variable approach relates the diurnal evolution of $2 \mathrm{~m}$-specific humidity $(q)$ and potential temperature $(\theta)$ to the surface and mixed layer energy balance and, in effect, the diurnal equilibrium established by L-A interactions. The daytime variability of $\theta$ and $q$ is sensitive to and integrative of the dominant processes involved in LoCo, and when plotted in energy space $\left(L q\right.$ vs. $\left.C_{p} \theta\right)$ can be used to quantify these processes.

Figure 1 presents a mixing diagram of the temporal change in $L q$ vs. $C_{p} \theta$ as generated by a mesoscale model and representative of conditions during June 2002 at a point in Oklahoma. For a full derivation and discussion of this theory we refer the reader to Betts (1992). The temporal change from $t_{i}$ to $t_{f}$ is fully described by vector components that represent the fluxes of heat and moisture from the land surface $\left(\mathbf{V}_{\text {sfc }}\right)$ and the top of the PBL (i.e. entrainment; $\left.\mathbf{V}_{\text {ent }}\right)$. These two vectors have a slope exactly equal to the Bowen ratio of the surface $\left(\beta_{s f c}\right)$ and entrainment $\left(\beta_{\text {ent }}\right)$, respectively. Their magnitude of their components, in terms of $C_{p} \Delta \theta$ and 
$L \Delta q$, are proportional to the fluxes of heat $(H)$ and moisture $(L E)$ of each, respectively. For example, the magnitude of the surface vector component in the y-direction (heat) is as follows,

$$
C_{p} \Delta \theta_{s f c}=\frac{\overline{H_{s f c}} \cdot \Delta t}{\rho_{m} \cdot P B L H}
$$

which can be calculated from the mean surface sensible heat flux $\left(H_{s f c}\right)$ over the timestep $\left(\Delta t=t_{f}\right.$ $\left.-t_{i}\right)$, the specific heat $\left(C_{p}\right)$, the density in the mixed layer $\left(\rho_{m}\right)$, and the mean height of the mixed layer $(P B L H)$ over $\triangle t$. PBLH therefore represents the volume by which the fluxes are scaled and can be defined as a suitable average of the depth of the PBL over the timestep (see Section 2b2) below). Note also that in Eq. 1 we have assumed that $\theta$ and $T$ are nearly equivalent at 2 meters (i.e. $\left.(\theta / T) \cdot H_{s f c}=H_{s f c}\right)$.

Once the surface vector $\left(\mathbf{V}_{\text {sfc }}\right)$ is computed, the heat entrainment flux $\left(H_{\text {ent }}\right)$ can be calculated from the component $\left(C_{p} \Delta \theta_{\text {ent }}\right)$ of the residual vector that connects $\mathbf{V}_{\text {sfc }}$ to the final values of $C_{p} \theta$ and $L q$ at $t_{f}$. The analogous formulation for components in the x-direction ( $L \Delta q_{s f c}$, $L \Delta q_{\text {ent }}$ ) is then used to derive to the fluxes of moisture at the surface (evaporation; $L E_{s f c}$ ) and top of the PBL (dry air entrainment; $L E_{\text {ent }}$ ). Figure 1 also shows the hourly time series of $\theta$ and $q$, $H_{\text {ent }}$, and $P B L H$ in a more traditional sense, and in this example highlights the mid-late afternoon decrease in moisture and rise of the PBL associated with increased dry air entrainment.

Having derived the slope $\left(\beta_{\text {ent }}\right)$ and magnitude $\left(C_{p} \Delta \theta_{\text {ent }}\right)$ of $\mathbf{V}_{\text {ent }}$, the entrainment ratio $\left(A_{R}\right.$ $=H_{\text {ent }} / H_{s f c}$, defined as the proportion of heat input to the PBL from entrainment to that of the surface, can be easily quantified. Typically, estimates of $A_{R}$ are difficult to acquire and there has been little consensus as to what the value should be based on different empirical studies (Kustas and Brutsaert 1987; Betts and Ball 1994). The mixing diagram approach is extremely valuable in this regard, considering that difficulties in observing and measuring fluxes at the top of the 
PBL greatly limit efforts to close energy budgets in the PBL (e.g., Peters-Lidard and Davis 2000; Santanello et al. 2005). Similarly, the entrainment of moisture (typically negative due to drier air in the free atmosphere) is easily quantified using this methodology. Therefore we find it useful to define separately a heat and moisture entrainment ratio ( $A_{h}$ and $A_{l e}$, respectively) when discussing the components of the energy budgets derived from mixing diagrams.

Betts (1992), Betts and Ball (1994) and Betts et al. (1996) provide the foundation for this approach and apply it to empirical data from short-term field experiments. They show how the diurnal evolution of $q$ and $\theta$ strongly reflects conditions and processes at the land surface (soil moisture, evaporation) and the top of the PBL (entrainment) as the theory suggests. A qualitative example is provided by Betts et al. (1996; their Fig. 8) that compare mixing diagrams for three days exhibiting different soil moisture conditions in Kansas. Although the vector and flux components are not explicitly calculated, a visual examination of these curves indicates the different evolution of temperature and humidity for dry, intermediate, and wet soils. In particular, the impact of entrainment is most notably visible in the mid-late day drying of the mixed-layer, and is most obvious for dry surface conditions. In contrast, wet surfaces evaporate more freely throughout the day, moistening the shallower PBL and reducing the magnitude of entrainment, and also evidenced in the diagrams.

\section{2) RELATION OF STEP-WISE INTEGRAL TO DIURNAL APPROXIMATION}

While the mixing diagram approach is relatively straightforward, it is important to address its applicability to the diurnal cycle as proposed here (Fig. 1). As indicated by Eq. 1, the derived fluxes and metrics are rather sensitive to the values of $H_{s f c}, P B L H$, and $\Delta t$, particularly early and late in the day when surface fluxes are small and the PBL is transitioning between nocturnal and convective behavior. To address this issue, we compared the results of applying 
the mixing diagram approach hourly (or step-wise, with values of $\theta, q, H_{s f c}$, and $P B L H$ varying at each hourly timestep) with those from a daytime mean (using the initial and final values of $\theta$ and $q$, and the mean values of $H_{s f c}$ and $P B L H$ between $t_{i}$ and $t_{f}$ ) calculation of the fluxes and ratios derived from the vector components. This was performed using output from the coupled mesoscale model employed in this study at the sites presented in Section 4a.

Despite lacking the finer temporal variability of the step-wise integration, the daytime mean fluxes $\left(R^{2}>0.98\right)$ and entrainment ratios $\left(R^{2}>0.97\right)$ at each site were found to correlate strongly with those calculated using hourly values averaged across the time period. While the step-wise approach is assumed to be more accurate, the small cost (MSE $\sim 25.0 \mathrm{Wm}^{-2}$ ) of simply using only the initial and final points with the mean flux and $P B L H$ throughout the day suggests the derived fluxes scale nearly linearly. Inspection of the variability of hourly flux and entrainment ratios throughout the day indicate that the highly sensitive time periods actually balance out, with higher entrainment ratios in the morning when surface fluxes are low (and therefore entrainment large in proportion) and lower ratios in the late afternoon when PBLH is large relative to surface fluxes. This results in the average fluxes and ratios over the entire period to be adequately represented by the daytime mean approach.

By using the theory outlined above, the exact nature of the L-A processes controlling PBL evolution, heat and moisture budgets, and their critical feedbacks can be evaluated in coupled models and compared against observations. It should be noted that the temporal dynamics (e.g. hourly evolution) of the fluxes and metrics can also be instructive in understanding the relative importance of PBL versus land surface processes in generating the daily mean L-A equilibrium. However, in terms of acquiring bulk information on L-A coupling 
throughout the day and being able to evaluate it using observations, the daytime mean approach remains more sensible and valuable.

\section{Model and Site Description}

a. WRF and LIS-WRF

The Advanced Research version of the Weather Research and Forecasting (WRF-ARW) model (Michalakes et al. 2001) is a state of the art mesoscale numerical weather prediction system. Derived from the Fifth-Generation NCAR/Penn State Mesoscale Model (MM5; Anthes and Warner 1978), WRF-ARW has been designated as the community model for atmospheric research and operational prediction and is ideal for regional simulations on the order of 1-7 days. The model has a Eulerian mass dynamical core and includes a wide array of radiation, microphysics, and PBL options as well as 2-way nesting and variational data assimilation capabilities.

To serve as a testbed for LoCo diagnostics, WRF-ARW (Versions 2.1.2/2.2) has been coupled to NASA's Land Information System (LIS; Versions 4.2/5.0) by Kumar et al. (2008). LIS consists of a suite of LSMs and provides a flexible and high-resolution representation of land surface physics and states which are directly coupled to the atmosphere (hereafter referred to as LIS-WRF). The advantages of coupling LIS to WRF-ARW include the ability to spin-up land surface conditions on a common grid from which to initialize the regional model, flexible and high-resolution soil and vegetation representation, additional choices of LSMs that will continue to grow, and various plug-in options such as land data assimilation and parameter estimation. LIS-WRF has been tested extensively thus far over the U.S. Southern Great Plains (SGP), Florida, the Gulf of Mexico, and Korea. 
The LSMs employed in LIS for this study are the Noah LSM (Noah; Ek et al. 2003), and the Community Land Model Version 2.0 (CLM; Dai et al. 2003). Both models dynamically predict water and energy fluxes and states at the land surface, but vary in specific parameterizations and representation of soil and vegetation properties and physics. For example, the Noah LSM solves moisture and heat transport through 4 discrete soil layers while CLM solves for 10 layers. In addition, treatment of vegetation properties (such as Leaf Area Index and Vegetation Fraction) and canopy fluxes differ between the two LSMs. The Noah model employed in this study is Version 2.7.1 and is identical to the version of Noah packaged in the original version of WRF-ARW. CLM is unique to LIS-WRF, and also serves as the land model for NCAR's coupled Community Climate System Model (CCSM). As such, these two LSMs are widely-used and capture the range in complexity (layering and vegetation physics) and application (mesoscale to global climate model) of schemes evaluated during the PILPS experiments.

There are three options for PBL schemes in WRF-ARW, all of which are employed in this study using LIS-WRF. The Medium-Range Forecast (MRF; Hong and Pan 1996) scheme is based on non-local-K theory (Troen and Mahrt 1986) mixing in the convective PBL, where the diffusion and depth of the PBL are a function of the Richardson number $\left(\mathrm{Ri}_{\mathrm{cr}}\right)$. The Yonsei University (YSU; Hong et al. 2006) scheme, based on the MRF, is also a non-local K theory implementation, but includes explicit treatment of entrainment and counter gradient fluxes. Finally, the Mellor-Yamada-Janjic (MYJ; Janjic 2001) scheme is the most complex PBL scheme, and employs nonsingular level 2.5 turbulent kinetic energy (TKE) closure (from Mellor and Yamada 1982) with local-K vertical mixing. In the MYJ scheme, the length scale is a function of TKE, buoyancy, and shear, and the PBL Height is diagnosed based on TKE production. 
Overall, these three PBL schemes span the range in complexity ( $1^{\text {st }}$ order to TKE) and application (single column to full 3-D) of those employed in the GABLS experiments. We therefore expect the results to encapsulate the wide range of coupling possible between LSMs and PBLs participating in PILPS and GABLS.

To address LoCo under the LIS-WRF framework, simulations were performed using the Noah and CLM LSMs with the MRF, YSU, and MYJ PBLs, for a total of 6 different combinations of L-A coupling (the remainder of the LIS-WRF setup is identical for each). The results of each experiment is then evaluated using the mixing diagram approach described above, where the processes and feedbacks generated by each LSM-PBL pair are quantified over the course of the day for different locations and conditions and compared with observations.

\section{b. LIS-WRF Experimental Design}

As shown by Koster et al. (2004) and others, the SGP region is a hotspot for L-A coupling in terms of the strength of interactions and feedbacks. Because of this, and the wealth and record of observational data from the Atmospheric and Radiation Measurement (ARM) testbed located in the region (ARM-SGP), numerous intensive field campaigns have been conducted in the region that have augmented the instrument and data quality even further. For this study, simulations have been performed for the International $\mathrm{H}_{2} \mathrm{O}$ Project in June 2002 (IHOP-02; Weckworth et al. 2004). During IHOP-02, we chose to focus on 36-hour simulations beginning at $00 \mathrm{Z}$ on June 6 and June 12, as they represent a clear-sky 'golden' day, and an unstable day with spatially heterogeneous convection, respectively.

LIS-WRF simulations were performed over a large single domain (900x600), centered over the Oklahoma and Kansas border near the ARM-SGP central facility (CF) at Lamont, OK, with a horizontal resolution of $1 \mathrm{~km}$ and timestep of $5 \mathrm{~s}$. The vertical grid of WRF-ARW uses an 
$\eta$ level-formulation, and was specified with 45 levels and a lowest model level of 42 meters.

Notably, there are approximately 21 model levels below $600 \mathrm{mb}$ (4-5 km; the maximum depth of the mixed layer) which enables PBL structure and processes to be highly-resolved. Other model specifications include a 5 second advection timestep, Ferrier microphysics, RRTM (Dudhia) log wave radiation, Goddard short wave radiation, and Monin-Obukhov surface layer scheme, while the North American Regional Reanalysis (NARR; Mesinger 2006) data was used for atmospheric initialization and lateral boundary conditions using 3-hourly nudging. Because the focus of these simulations are on the sensitivity of PBL-LSM couplings and how they are reflected in L-A variables (rather than the absolute accuracy and experiment design), we have not included all remaining specifications of LIS-WRF here that are identical for all simulations.

For each experiment, LIS-Noah and LIS-CLM were run offline (uncoupled) for the 3.5 year period prior to the start time of IHOP-02 to create equilibrated, or spun-up, land surface states for initialization of LIS-WRF. For example, Fig. 2 shows the upper layer $(0-10 \mathrm{~cm})$ soil water content over the $1-\mathrm{km}$ resolution IHOP-02 domain as generated by the Noah spinup valid at $12 \mathrm{Z}$ (this procedure was repeated for CLM and for the IHOP-02 June 6 experiments for each LSM). The high spatial resolution seen in Fig. 2 is a reflection of the inputs of land cover, vegetation, and soil properties available in LIS. Overall, land surface conditions in the ARMSGP region range from highly vegetated and moist in the east to increasingly bare and drier soils in the west.

c. ARM-SGP Observations

The ARM-SGP program provides surface flux, meteorological, and hydrological observations along with atmospheric profiles for a network of sites in and near the winter wheat belts of Oklahoma and Kansas. This field experiment has been widely used in previous studies 
and information on the site locations and characteristics is available at Www.arm.gov/sites/sgp.stm.

Radiosondes are launched daily at approximately 1130, 1430, 1730, and 2030 UTC (6:30am, 9:30am, 12:30pm, and 3:30pm local solar time) at the SGP central facility at Lamont, OK (CF). For this work, radiosonde measurements of temperature, dewpoint, and pressure were converted to profiles of $\theta$ and $q$ at $\sim 10 \mathrm{~m}$ vertical resolution using standard thermodynamic relationships, from which estimates of the height of the PBL (inversion of $\theta$ at the top of the mixed layer) were derived.

The ARM-SGP site employs both Bowen ratio (EBBR) instruments at CF as well as numerous extended facilities throughout Kansas and Oklahoma. These data include 30-minute average fluxes of net radiation, sensible, latent, and soil heat, along with co-located surface radiant temperature, 2-m air temperature, mixing ratio, and wind measurements from micrometeorological instrumentation.

\section{Results}

The following sections present mixing diagrams generated from LIS-WRF simulations of the IHOP 6 and 12 June 2002 experiments. As described above, generation of these plots and derived metrics requires only the diurnal evolution of $\theta$ and $q$, and mean $H_{s f c}$ and $P B L H$ over the time period, which are variables routinely output from LIS-WRF and observed at ARM-SGP.

\section{a. Mixing diagrams and derived metrics}

The principal controls on the fluxes of heat and moisture from the surface reside in the degree of soil moisture and vegetation cover. During spring and summer over the ARM-SGP region, there is high spatial variability in each of these (as shown in Fig. 2) that we can use to examine LoCo across a range of conditions. Figure 3 presents mixing diagrams from LIS-WRF- 
Noah and LIS-WRF-CLM simulations on 12 June 2002 for a location with dry soil moisture conditions $\left(0.11 \mathrm{~m}^{3} \mathrm{~m}^{-3}\right.$ and $0.08 \mathrm{~m}^{3} \mathrm{~m}^{-3}$ for Noah and CLM, respectively) in the western and bare soil region of the domain. The impacts of coupling the three PBLs to each LSM can be seen in the differences in the evolution of $\theta$ and $q$.

Qualitatively, the overall shape of the curves indicates little evaporation from the surface and significant dry air entrainment into the PBL. The metrics derived from these diagrams are also plotted and confirm a high $\beta_{s f c}$ and surface heating, while the entrainment flux is primarily that of dry air $\left(\beta_{\text {ent }}<-0.50\right)$ that results in significant PBL drying and growth throughout the day. The large magnitudes of $A_{h}$ and $A_{l e}$ confirm that the entrainment fluxes of heat and moisture dominate over the surface fluxes, which correspond to rapid and deep PBL growth over a dry surface as the values for maximum $P B L H$ are each well over $3 \mathrm{~km}$. All six PBL-LSM combinations also indicate a well-established elevated (residual) mixed-layer at the initial time that is very unstable, and once this level is reached leads to the explosive and deep PBLs (and entrainment fluxes) simulated at this site. In fact, this type of mixing diagram 'signature' is indicative of an entrainment feedback loop that supports deep PBL growth, drying of the PBL, and desiccation of the surface moisture condition leading to drought if persistent over time (as described in Santanello et al. 2007).

The subtle but significant differences within and between the two diagrams are reflective of differences in PBL-LSM coupling. For the Noah LSM (Fig. 3a), the equilibrium created with all three PBLs is very similar, with the YSU scheme exhibiting the largest entrainment of heat and dry air, and the MYJ scheme the least. This is confirmed in the vertical profile data (not shown), where the YSU has an extremely deep maximum PBLH $(4.9 \mathrm{~km})$ versus that of the MYJ $(3.5 \mathrm{~km})$, with the MRF scheme in between $(4.2 \mathrm{~km})$. 
For the CLM simulations (Fig. 3b), there is a noticeable difference in the coupling established with the 3 PBLs from that of Noah. All three CLM simulations exhibit greater warming of the PBL (along with comparable drying) than Noah, as reflected in the higher values of surface $\left(\beta_{s f c}>8.0\right)$ and entrainment $\left(\beta_{\text {ent }} \sim-0.50\right)$ heat fluxes. The sensitivity of CLM to the choice of PBL is also greater, as evidenced by the spread between curves in Fig. 3b. The surface fluxes produced by CLM are similar for each PBL with very little evaporation taking place, but the YSU scheme produces the largest heat and dry air entrainment amounts. It is also important to note that the MYJ scheme (as is also the case in Fig. 3a) produces a more slowly growing PBL as a result of the initial atmospheric profile being more stable than for the YSU/MRF schemes. Overall, the profiles indicate similar maximum $P B L H$ values to the Noah simulations for all three PBLs, and are reflective of a drying regime characterized by a desiccated, largely bare soil (26 percent vegetation fraction) surface with a deep residual mixed layer that supports significant PBL growth and entrainment impacts on the mixed-layer equilibrium.

Figure 4 presents mixing diagrams for intermediate soil moisture conditions $\left(0.18 \mathrm{~m}^{3} \mathrm{~m}^{-3}\right.$ for both Noah and CLM) in the ARM-SGP region as simulated by LIS-WRF using the Noah and CLM LSMs. For all PBL-LSM combinations shown in Figs. $4 \mathrm{a}$ and $4 \mathrm{~b}$, there is a significantly different signature of $\theta$ and $q$ evolution than for dry soils. Most significantly, there is little diurnal variability in $q$ and a lower dynamic range in $\theta$, which is expected due to the PBL-LSM equilibrium created over a more moist and vegetated (40 percent vegetation fraction) surface.

As described by the metrics, more energy at the surface goes to evaporation $\left(\beta_{s f c}\right)$ from the moister soil at this location, which lowers the amount of surface heating and flux of heat into the PBL. There is also less buoyancy and slower PBL growth simulated in each that is reflected in the much lower proportion of heat and dry air entrainment $\left(A_{h}, A_{l e}\right)$ than for dry soils. The 
damped evolution of $q$ is a result of the magnitudes of surface evaporation relative to that of dry air entrainment, which nearly balance for this location. In this case, there is near zero flux of heat into the PBL from entrainment, with some simulations (Noah-YSU and Noah-MRF) actually indicating some slightly cooler air mixing through the inversion. Maximum $P B L H$ was approximately $1.6 \mathrm{~km}$ for the MRF and MYJ simulations, while the YSU was slightly higher ( $1.8 \mathrm{~km}$; not unexpected given the difference in physics and explicit entrainment treatment in the YSU scheme). Given the close similarity of the three curves and derived fluxes within each plot, these results also suggest that the PBL-LSM equilibrium is more significantly impacted by the choice of LSM than by the particular PBL scheme employed. However, the impact of each LSM and their surface fluxes is diminished at this location due to a strongly stratified initial profile that limits PBL growth, and will be discussed further in Section 4c.

Figure 5 presents mixing diagrams for wet soil conditions $\left(0.32 \mathrm{~m}^{3} \mathrm{~m}^{-3}\right.$ and $0.40 \mathrm{~m}^{3} \mathrm{~m}^{-3}$ for Noah and CLM, respectively) in the eastern portion of the domain, which is also more heavily vegetated ( $>90$ percent vegetation fraction). What is immediately evident for the Noah simulations in Fig. 5a is the small range in both $\theta$ and $q$ and the dominance of the moisture flux controlled by a nearly freely evaporating surface (low $\beta_{s f c}$ ) and limited PBL growth and heat entrainment (low $\beta_{\text {ent }}$ ). The pattern and fluxes from each of the three PBL schemes is similar, and there is very little surface heating and PBL growth $(<1.4 \mathrm{~km})$ for this location as well. One interesting feature of this plot is the strong inflection point in $q$ near midday (19 LST); where there is a transition from slowly decreasing to rapidly increasing moisture in the PBL. This suggests the possibility of a significant horizontal advection component in the system, and will be addressed in Section 4e. 
The CLM simulations (Fig. 5b) produce somewhat different signatures of heat and moisture fluxes and PBL evolution at this location. Most notably, surface evaporation is dominant, and $\beta_{s f c}$ near zero due to an initial soil condition for CLM that is near saturation. There is also a slightly larger diurnal range in temperature than for Noah (higher $\beta_{\text {ent }}$ ), which combined with the near zero surface heat flux produces a higher entrainment (i.e. residual) flux estimate. This is partially a result of greater PBL growth in the CLM simulations ( $P B L H \sim 1.6$ $\mathrm{km}$ ), though limited as the initial profiles indicate strong stability for both Noah and CLM simulations. For all three PBL schemes over the wet surface, $A_{l e}$ is approximately equal to -1.0 which indicates the near balance of evaporation with entrainment, but also includes the inflection point noted in Fig. 5a. In this case, the diagrams indicate that the choice of LSM is as or more important to the simulated L-A equilibrium than the particular PBL scheme employed. This follows in that the high moisture availability at the surface and resultant energy balance dominate the potential for mixed layer growth and, as a result, the PBL budget over wet surfaces.

\section{b. PBL budget evaluation}

Mixing diagrams contain a wealth of information that can also be synthesized from an energy balance perspective to quantify the variability and accuracy of the processes that govern PBL evolution that are difficult to measure. To summarize the L-A processes quantified in these mixing diagrams and their sensitivities to different surface moisture conditions, Table 1 lists the daily mean heat and moisture fluxes from the surface and entrainment derived from the component vectors in Figs. 3-5. The values of these fluxes support the interpretation of the diagrams and metrics presented above and highlight the decreasing (increasing) impact of dry air entrainment (surface evapotranspiration) from dry to wet soils. Further, these fluxes as a whole 
define the total heat and moisture budgets of the PBL, and as such define the relative contribution of the surface versus atmospheric fluxes.

Similar to analyses performed for the PILPS experiments (e.g. Chen et al. 1997b, Pitman et al. 1999), the relationship of daily mean $H$ and $L E$ can be plotted for each PBL-LSM combination. While PILPS was limited to surface fluxes in an offline intercomparison, the fluxes derived here also include those of entrainment, thereby defining the processes contributing to the total PBL heat and moisture budget. Following this approach, Fig. 6 shows the relationship between sensible and latent heat fluxes from the surface and entrainment for each of the simulations at the dry, intermediate, and wet soil locations shown in Figs. 3-5 and listed in Table 1.

At the dry site, the extremely vigorous PBL development corresponds to the dry air and heat entrainment dominating the PBL budget, with is a noticeable sensitivity to the PBL scheme employed. The surface fluxes are a much smaller proportion of the total budget, and are similar (low $L E_{s f c}$, high $H_{s f c}$ ) across all LSMs. For intermediate soils, there is more of a balance between surface and entrainment fluxes from which the sensitivities of each to the choice of LSM becomes more apparent. However, all six simulations result in a net moisture flux in the PBL of approximately $-100.0 \mathrm{Wm}^{-2}$, as differences in PBL and surface fluxes cancel out. The sensitivity of the PBL budget components to the choice of LSM is more evident for wet soils (Fig. 6c), where there is a near balance of evaporation and entrainment $\left(L E_{\text {tot }} \sim 0.0 \mathrm{Wm}^{-2}\right)$ along with limited heating of the PBL $\left(H_{t o t}<200.0 \mathrm{Wm}^{-2}\right)$, and evidenced by the shallow PBL growth at this site.

Although there are no flux observations at these three locations, the surface fluxes can be compared against a theoretical line of constant net radiation $\left(500 \mathrm{Wm}^{-2}\right)$, which shows how 
available energy at the surface increases for all simulations over wet soils due to changes in albedo and surface temperature. This also highlights that the surface available energy varies between LSMs, particularly at the intermediate and wet sites, and that the partitioning of fluxes for a given LSM varies due to the choice of PBL coupling. Overall, the transition of surface fluxes to higher $L E_{s f c}$ and lower $H_{s f c}$ from dry to wet conditions is as expected, and in effect the patterns observed in these diagrams describe a transition in the PBL from a drying (entrainment dominated) regime to a moistening (surface dominated) regime.

\section{c. Integrative diagnostics of LoCo}

The vectors and fluxes derived in Figs. 3-6 are, from a slightly broader perspective, reflected in two observable properties of the system that are a direct function of the L-A equilibrium generated by each PBL-LSM coupling. First, the forcing from the land surface $\left(H_{s f c}\right.$ in Eq. 1) is best represented by the evaporative fraction $\left(E F=L E_{s f c} /\left(H_{s f c}+L E_{s f c}\right)\right)$, which is a function of the flux of heat and moisture from the land to the atmosphere that contributes to the buoyancy and evolution of the PBL. $E F$ is similar to the Bowen ratio but normalized for incoming available energy, and is sensitive to soil moisture availability as it controls the surface flux partitioning. The second integrative property that is sensitive to the PBL-LSM coupling is PBL height (PBLH in Eq. 1), as it is a direct function of the fluxes (most notably heat and dry air entrainment) that determine PBL evolution.

Combined, the relationship between daily mean $E F$ and maximum $P B L H$ can be thought of as describing the amount of surface forcing generated by a LSM versus what the response of the coupled PBL scheme is relative to those fluxes. Figure 7 shows an example of this relationship as simulated by the LIS-WRF model for the dry, intermediate, and wet soil sites depicted in Figs. 3-5. As was shown in Fig. 3, there is significant PBL growth and entrainment 
fluxes over dry soils that are supported by the low $E F$ and very high $P B L H$ values seen here. The Noah and CLM simulations with the MYJ PBL showed a slightly different evolution of $\theta$ and $q$ and lower entrainment rates $\left(A_{h}\right.$ and $\left.A_{l e}\right)$ than the YSU/MRF schemes, which is reflected in the lower maximum $P B L H$ reached despite having similar low values of $E F$ and high surface heating. In this case, the PBL scheme (atmosphere) limits the impact and dampens the forcing from the land surface.

It should be noted that the noticeable differences in the evolution of $\theta / q$ and $E F / P B L H$ produced by the YSU/MRF versus the MYJ scheme thus far are not unexpected given the type of turbulence closure employed by each scheme. The non-local diffusion parameterized in YSU/MRF is known to be more accurate for convective PBL evolution and depth, while the 2.5 order local closure of the MYJ scheme simulates the nocturnal PBL more accurate and typically underestimates the convective PBL (Stensrud 2007). In addition, CLM is traditionally coupled with CCSM, which employs a non-local K theory in the PBL similar to that of YSU/MRF.

For dry and intermediate soil moistures, the CLM simulations produce a slightly lower $E F$ (higher $H_{s f c}$ ) than the corresponding Noah runs. This is partly due to the CLM spinup initializing a slightly drier soil than Noah for these locations, but also due to the differences in LSM physics controlling evaporation. For wet soils, the reverse is true where $E F$ is slightly higher in CLM due to slightly higher initial soil water content from the CLM spinup (i.e. despite that the spinups used identical atmospheric forcing as for Noah, the model climatology of CLM tends to produce higher $E F$ on this date). It is also important to note that the variability in $E F$ between Noah and CLM shown here corresponds directly to the differences in $\mathbf{V}_{\text {sfc }}$ that were discussed in Figs. 3-5. 
For intermediate soils, PBL growth is limited $(<2.0 \mathrm{~km})$ for Noah and CLM despite the fact that $E F$ is low and there is strong surface heating (comparable to the dry site) simulated by each. This is due to the atmospheric stability and thermal stratification over this site being significantly more stable than over the dry site. Specifically, the initial (12Z) stability in the lower $3 \mathrm{~km}$ of the atmosphere over the intermediate site is approximately $2.6 \mathrm{~K} / \mathrm{km}$, while the dry site exhibits a much weaker inversion of $4.3 \mathrm{~K} / \mathrm{km}$ and a deep elevated residual layer. It follows (as shown in Fig. 4) that there is only moderate entrainment of heat or moisture, and therefore the atmosphere is the dominant control on PBL evolution for the intermediate site. As such, PBL evolution is largely insensitive to the choice of LSM, and due to the strong stability is also largely insensitive to the choice of PBL scheme and turbulence parameterization employed by each.

For wet soils, there is slightly higher PBLH simulated by CLM despite having a wetter surface and higher EF than Noah. This follows with Figs. 5 and 6c, which showed a greater rise in CLM mixed layer temperature and entrainment into the PBL than in the Noah simulations. There is also slightly more variability in the co-evolution of $\theta$ and $q$ between simulations due to the choice of PBL scheme than for intermediate soils. However, the most significant differences occur in EF simulated from CLM and Noah, which along with the results of Figs. 5 and 6c suggests that the choice of LSM is the more critical component of L-A coupling for this site. As such, evaluating the relationship of $E F$ and $P B L H$ enables the relative strengths and weaknesses of the schemes to be identified in terms of observable, integrative properties of the L-A system established by each PBL-LSM coupling. There is, as expected, greater sensitivity of $E F$ to the choice of LSM and moisture regime, while $P B L H$ varies more significantly between PBL 
schemes and particularly for drier soils and when the impacts of the entrainment feedbacks are maximized.

Overall, the series of plots presented in Sections 4a-c have demonstrated the power and relative ease of using mixing diagrams to evaluate L-A interactions, as well as their sensitivities to differences in PBL-LSM couplings and surface and atmospheric conditions. When combined, the three approaches presented above (mixing diagrams, PBL budgets, and $E F$ vs. $P B L H$ ) provide a comprehensive analysis of the processes governing LoCo in a manner that synthesizes the complex interactions and feedbacks into a quantitative and observable framework, while offering the ability to directly evaluate the PBL and LSM fluxes and schemes, and sensitivities of each.

\section{d. Mixing diagrams with observations}

This approach can now be supplemented with observations in order to evaluate these simulations in the context of the impacts and accuracies of different PBL-LSM couplings. It should be noted that it is not the goal of this study to perform an intensive evaluation of the physics of the PBL and LSM schemes employed here, but rather to use these experiments to demonstrate a framework to further evaluate and understand any coupled modeling system.

Mixing diagrams from LIS-WRF simulations are presented in Fig. 8 with observations made at the ARM-SGP Central Facility (CF; E13) on 6 June 2002. The Noah simulations with all three PBLs generally capture the observed evolution of $\theta$ and $q$. A closer examination of the curves shows that the shift of slope towards negative $q$ (due to dry air entrainment) occurs near midday in both the simulations and observations, and there is general agreement in the patterns of $\theta$ and $q$ with observations throughout the afternoon including a small increase in $q$ at $23 \mathrm{Z}$ when PBL growth and entrainment shuts down. In addition, despite that the metrics show that 
the Noah model simulates higher $\beta_{s f c}$ values the PBL heights generated by the YSU, MYJ, and MRF schemes $(1.4,1.6$, and $1.3 \mathrm{~km}$, respectively) are close to observed $(1.5 \mathrm{~km})$. This suggests that the impact of surface fluxes generated by the LSM is minimal in influencing the evolution of PBL properties.

In contrast, the diurnal patterns of the CLM simulations tend to diverge appreciably from the observations and from Noah, and show significant early moistening followed by rapid drying due to entrainment. This is a situation where the $12 \mathrm{Z} / 00 \mathrm{Z}$ and daily mean values are reasonable, but the actual hourly evolution of $\theta$ and $q$ (as well as the mean fluxes) do not reflect reality. Once again, all three simulations in Fig. $8 \mathrm{~b}$ overestimate $\beta_{s f c}$ and underestimate $A_{h}$, while the YSU scheme produces similar $\beta_{\text {ent }}$ and $A_{l e}$ values to those observed. The MRF simulation produces the deepest PBL $(1.6 \mathrm{~km})$, reflected in larger production of dry air entrainment than the other two schemes and observations. As was the case for Noah, the slopes of the entrainment vectors are quite close to that observed, indicating that regardless of the accuracy of surface flux partitioning (by the LSM) or magnitude of entrainment fluxes the ratio of dry air to heat being entrained is simulated quite well by all three PBL schemes, as is the maximum PBLH.

The mixing diagrams for the ARM-SGP facility at Plevna, KS (E4; north of the CF and slightly drier) are presented in Fig. 9 for the Noah and CLM simulations. The signatures of $\theta$ and $q$ are roughly similar to those in Fig. 8, with the Noah simulations noticeably more consistent and closer to observations than CLM. From Noah and observations there is less moistening of the mixed layer (through evaporation) and consequently higher surface heat fluxes than observed $\left(\beta_{s f c}>2.0\right)$, but once again the ratio of dry air being entrained is very close to that observed $\left(\beta_{\text {ent }}=-0.25\right)$ 
The CLM simulations show more sensitivity to the PBL scheme, but are closer to observed than in Fig. 8b. The YSU and MRF results are initially offset as too warm and moist, but the $\theta$ and $q$ evolution throughout the remainder of the day is very close to that observed. The MYJ simulation exaggerates the slight morning moistening of the PBL and as a result remains too moist throughout the day, which limits PBL growth $(<1.6 \mathrm{~km})$ compared to observations $(1.8 \mathrm{~km})$. All three PBLs simulate an exaggerated diurnal cycle (particularly in $\theta)$, and as a result also overestimate the residual vector $\left(\mathbf{V}_{\text {ent }}\right)$ and the proportion of heat versus dry air being entrained $\left(\beta_{\text {ent }}>>-0.25\right)$ relative to that observed.

The PBL budget and $E F / P B L H$ diagnostics can now be examined to further understand the nature of the L-A coupling created by each of the PBL-LSM pairings and how they compare to observations at these two sites. Fluxes comprising the PBL budget of heat and moisture from the E13 and E4 sites (shown in Figs. 8 and 9) are shown in Fig. 10. Also included are the observed fluxes derived from the mixing diagrams and lines of constant energy $\left(H_{s f c}+L E_{s f c}\right)$ observed at the land surface. At the E13 site, the surface fluxes from each simulation align below the observed available energy, with the flux partitioning biased $\left(\sim 100 \mathrm{Wm}^{-2}\right)$ towards higher $H_{s f c}$ and lower $L E_{s f c}$ than observed (as reflected in the slopes of $\mathbf{V}_{\text {sfc }}$ in Fig. 8). On the other hand, the entrainment and total PBL fluxes indicate a greater spread in energy partitioning, with an underestimation of $H_{\text {ent }}$ that is primarily greater than the overestimation of heat flux from the surface. When compared against the observed total fluxes (i.e. budget), this results in four of the six simulations underestimating the net total heat flux into the PBL at this site. Likewise, there is more dry air entrainment than evaporation of moisture into the PBL, leading to a negative input of moisture into the PBL from all six PBL-LSM combinations. 
At the E4 site (Fig. 10b) a similar pattern emerges in that the available energy and evaporation at the surface are underestimated in all simulations, but unlike E13 there is a clear sensitivity to the choice of LSM. This follows for entrainment as well, where Noah (and in particular Noah-YSU) simulates dry and heat entrainment fluxes very close to those observed. As the mixing diagrams in Fig. 9 indicate, CLM produces too much heat entrainment at the expense of dry air. Therefore, because all six PBL-LSM couplings produce too little evaporation, the total moisture budget from Noah (CLM) is too dry (wet), while the heat input to the PBL is slightly overestimated in each.

With the addition of observations to the $E F / P B L H$ diagnostics, it can also now be ascertained if each PBL-LSM coupling produces the 'correct' answer (e.g. $P B L H$ ) despite flaws in the representation of specific L-A processes (e.g. surface fluxes, entrainment). Figure 11 presents the relationship of $E F$ and maximum $P B L H$ at the E13 and E4 sites along with observations. As suggested by the PBL budget results at E13, there is not a clear indication that the PBL or LSM choice is more important than the other, and the PBL growth is sensitive to the precise nature of the PBL-LSM coupling. When combined with Fig. 11a, however, it can be ascertained that the two outlier points in Fig. 10a that overestimate the total heat budget $(\sim 400$ $\mathrm{Wm}^{-2}$ ) are also the same PBL-LSM couplings (Noah-MYJ and CLM-MRF) that are outliers in terms of $E F$ and $P B L H$. The remaining four simulations produce less PBL growth, and all simulations estimate significantly lower surface evaporation than observed.

The relationships at the E4 site show a clear sensitivity to the choice of LSM, with CLM producing higher evaporation (in response to a slightly wetter soil than Noah) throughout the day and in return diminished PBL growth compared to Noah and observations. This is confirmed in the PBL budget and mixing diagram results, where CLM underestimates the drying due to 
entrainment. Once again all PBL-LSM couplings underestimate the $E F$, and at this site the observed maximum $P B L H$ is not reached by any of the simulations. This may be due to the fact that the surface available energy is too low, thereby limiting evaporation and also the buoyant energy at the surface.

Overall, the combination of the three approaches (Figs. 8-11), with their foundation in the mixing diagram approach and the addition of observations, can be useful in diagnosing the accuracy and sensitivity of land surface and PBL state variables, fluxes, and bulk PBL properties. For example, while CLM does a poorer job than Noah of simulating the diurnal evolution of $\theta$ and $q$ at E13 and E4, there is clearly more sensitivity to the choice of LSM at site E4 (as evidenced in Figs. 10 and 11). Furthermore, flux biases (such as that shown in Fig. 10a for $H_{\text {ent }}$ ) can be diagnosed that indicate errors in the amount of energy supplied at the land surface and/or into the PBL through entrainment created by a particular PBL-LSM coupling. These are all important steps towards greater and complete understanding and quantification of the components of LoCo.

\section{Discussion}

The mixing diagram theory presented by Betts (1992) also supports inclusion of a horizontal advection vector. As many studies have shown (Kustas and Brutsaert 1987; PetersLidard and Davis 2000; Santanello et al. 2005), one of the main limiting factors (other than entrainment) in closing the heat and moisture budgets of the PBL is advection. Here, horizontal advection of heat and moisture can be represented by a vector $\left(\mathbf{V}_{\text {adv }}\right)$ in the same manner as the surface and entrainment fluxes, and represents the horizontal flux of heat and moisture over the time period. The contribution of advection is calculated and then added to the surface flux vector $\left(\mathbf{V}_{\text {adv }}+\mathbf{V}_{\text {sfc }}\right)$, with the new residual representing the entrainment flux as depicted in Fig. 
12. As such, the surface flux vector is unaffected by the addition of advection, while entrainment clearly is impacted to a degree determined by the magnitude and direction of the advection vector. The advection Bowen ratio $\left(\beta_{a d v}\right)$ and component fluxes $\left(H_{a d v}, L E_{a d v}\right)$ are then computed in analogous fashion to the surface and entrainment contributions to the PBL budget. The high-resolution of LIS-WRF output ( $1 \mathrm{~km}$; hourly) makes it relatively easy to calculate hourly advection estimates using a finite differencing approach and to re-generate mixing diagrams that include all three PBL budget components.

Figure 13 presents the mixing diagrams and for the wet soil site (as shown in Fig. 5) after the inclusion of the advection vectors. In the Noah simulations, the advection is in the cold and moist direction but rather small relative to the surface and entrainment vectors. In contrast, the CLM simulations produce more significant advection fluxes that are opposite in sign (warm and dry) to those from Noah. As such, the CLM advection is acting in the same direction as entrainment thereby lowering the magnitude of the residual vector $\left(\mathbf{V}_{\text {ent }}\right)$. This becomes evident in the flux values and PBL budgets plotted in Fig. 14. The original CLM mixing diagrams (ignoring advection) and results from Figs. 5-7 indicate rather high estimates of entrainment fluxes considering the high surface evaporation rate which limited surface heating and PBL growth at this site. In the new diagram, it is evident that advection is contributing to the warming and drying of the mixed layer, and as a result the surface evaporation can be thought of as being nearly balanced by entrainment and advection (i.e. $L E_{t o t} \sim 0.0 ; A_{l e, e n t}+A_{l e, a d v} \sim-1.0$ ).

The magnitude of the advection vector for the CLM makes it an important addition to the mixing diagram approach and interpretation of its derived metrics and fluxes. However, this is not the case for Noah or the other sites and results presented earlier, where advection and the resultant impacts on L-A coupling processes and PBL budgets were minimal. While the 
inclusion of advection does not impact the surface or total energy budget value, or the relationship between $E F$ and $P B L H$, it should still be considered on a case by case basis as it may comprise a large component of the residual vector and can easily be applied as shown here.

In terms of the residual (entrainment) vector itself, it can best be put in terms of an 'atmospheric response' vector in that it represents the full sum of atmospheric fluxes and contribution to PBL evolution. While entrainment was shown to be dominant for the case studies selected here, this list includes processes such as advection, radiative flux divergence, compressional warming, and moist processes such as condensation/evaporation at the top of the PBL. The clear sky focus and approach taken here can therefore be expanded (as for advection) to account for these processes as additional components of the residual vector, should they be significant.

An important application of mixing diagrams is the ability to evaluate coupled systems in terms of the accuracy of their component surface and PBL schemes. In comparing the evolution of $\theta$ and $q$, fluxes, and bulk PBL properties (e.g. $P B L H$ ) to other models and observations, deficiencies in the various schemes' production of turbulent fluxes can be pinpointed. Typically, LSMs are evaluated offline and against individual variables or fluxes. Using the approach presented here, however, modifications to LSM parameters or physics can be implemented and their impacts on simulated surface variables and fluxes can be evaluated along with the corresponding atmospheric response in the form of PBL evolution and budgets (i.e. the residual vector). Using the $\mathrm{E} 4$ site above as an example, modifications to increase surface available energy and evaporation in the LSM scheme would certainly impact the turbulent fluxes and evolution of the PBL (including non-linear feedback effects), resulting in a new equilibrium between L-A processes as reflected in the diagrams. The impact and sensitivity of each coupled 
system to modifications to the LSM (or PBL) can therefore be quantified in terms of changes to the vector components and PBL budgets.

The mixing diagram approach can also be used to identify poorly understood L-A feedback regimes in coupled systems. For example, the feedback of dry air entrainment on the evolution of surface fluxes can be a significant determinant of the diurnal L-A equilibrium created between the PBL and land surface (Santanello et al. 2007). Figures 3-7 showed the differences in this equilibrium across surface moisture regimes, but also highlight the feedback of dry air entrainment in a) maintaining a nearly constant evaporative demand and moisture budget in the PBL at the intermediate and wet sites, and b) supporting extremely vigorous PBL growth and dry air entrainment due to the presence of an elevated residual mixed layer at the dry site. These feedbacks tend to be self-perpetuating, so identification of each is important in evaluating various PBL-LSM couplings and their limitations. Further, the stratification over surface moisture regimes could easily be performed over varying land cover, vegetation, soil, or atmospheric properties to evaluate the sensitivities of the coupled system to a wide range of conditions.

There are potential issues relating to scale when applying these methods that must be addressed as well. The LIS-WRF experiments were run at very high spatial resolution $(1 \mathrm{~km})$, and for the analyses presented here a single grid cell, or column, was pulled out nearest to the site of interest. Clearly, there is heterogeneity in land and atmospheric properties around each cell that may impact the evolution of PBL properties and fluxes. Therefore, additional analyses were performed using mixing diagrams created from columns taken from up to $25 \mathrm{~km}$ surrounding each point of interest. It was found that, while there is variability in $\theta, q$, and PBL evolution around each site, differences were small relative to the overall patterns observed and 
characteristics of the central location, and therefore did not impact the demonstration of the approach or interpretation of results. In addition, the surface flux, temperature, and humidity observations are point measurements, and best evaluated at that point rather than an areal average. Studies and locations that are more heterogeneous may require such an averaging approach, however, particularly with regards to PBL properties (e.g. $P B L H$ ) that integrate over a much larger region.

\section{Conclusions}

The framework and results presented here provide a comprehensive methodology to quantify and evaluate the critical processes controlling local L-A coupling. The ability to evaluate the full PBL heat and moisture budgets and their flux components is critical to identifying the dominant processes involved in LoCo as well as deficiencies in PBL and LSM schemes and their interactions and feedbacks. As was shown here, all the information necessary for such an analysis is contained in mixing diagrams, wherein the diurnal co-evolution of $\theta$ and $q$ is integrative of the processes controlling PBL growth and the resultant L-A equilibrium established. Overall, the combination of mixing diagrams with their derived metrics (e.g. entrainment and Bowen ratios), PBL budgets, and integrative diagnostics ( $E F$ vs. $P B L H)$ with observations supplies a consistent and practical framework from which to evaluate coupled models and parameterization schemes on diurnal time scales.

The IHOP-02 experiments and sites focused on here cover a wide range of surface moisture and atmospheric conditions from which to test the mixing diagram approach and its sensitivity to significant variability in PBL and land surface fluxes. The different 'signature' of each mixing diagram is quite evident, and reflects a strong sensitivity of the derived fluxes and metrics to these conditions and the various combinations of PBL-LSMs, and can be evaluated in 
combination with the PBL budgets and $E F / P B L H$ relationships. For dry soils, the PBL evolution and structure is more significantly impacted by the choice of PBL scheme than by the particular LSM employed. For intermediate soils, the diagrams indicate that neither the choice of LSM or PBL dominates the simulated L-A equilibrium due to a strongly stable atmosphere that constrains the system. For wet soils, there is more influence of the choice of LSM on the resultant PBL evolution and fluxes.

The ultimate utility of this approach is in evaluating coupled models and their scheme components against observations. The two ARM-SGP sites presented here (E13 and E4) show significant variability in $\theta / q$ signatures and derived fluxes due to the specific PBL-LSM coupling employed. The evaluation of PBL budget components as well as PBL height suggests that there is not enough available energy to support evaporation at the surface and that PBL turbulence is underestimated, the degree to which depends on the scheme choice. Modifications to these schemes therefore will result in a new L-A equilibrium that can similarly be evaluated against the observations. This is a major advantage of the methodology, in providing a truly coupled evaluation of the processes involved in terms of observable, integrative properties of the system, rather than a traditional one-at-a-time or offline approach.

The IHOP-02 experiments were provided as an example of how to apply the mixing diagram approach to model output and observations. While the focus is on diurnal and local scales for convective PBLs, this framework can be easily applied to any coupled model, scales, and conditions of interest. Although the focus was on cloud-free and smooth diurnal cycles, the mixing diagram framework used in this study includes the full set of governing L-A interactions and processes that allows for other applications. For example, the entrainment Bowen ratio $\left(\beta_{\text {ent }}\right)$, shown to be an important determinant of convective initiation (Betts and Ball 1994) yet 
difficult to measure, is one of the principal metrics derived from this approach. Such metrics would be valuable to understanding the generation of convection in coupled models by quantifying the L-A processes and feedbacks that are typically difficult to interpret (Trier et al. 2004; Holt et al. 2006).

Ongoing work on advancing the cause of LoCo includes a number of detailed experiments and analyses based on the mixing diagram approach. For example, an evaluation of different methods to spinup Noah and CLM and initialize LIS-WRF is being performed with varying degrees of input forcing and parameter data quality to yield insight into the sensitivity and accuracy of various PBL-LSM couplings to the initial conditions. Another ongoing experiment is an extended ( 7 day) regional simulation that will enable LIS-WRF to evolve over time from synoptically forced, clear-sky conditions with a drydown period ending with the convectively-active 12 June case. As such, a longer-term transition can be seen in the mixing diagrams from each day that reflects the changing surface and atmospheric conditions through the evolution of $\theta$ and $q$.

In addition, this framework will be included in an upcoming GEWEX-GLASS directed community-wide set of pilot experiments, where LIS-WRF will serve as the testbed. This study will evaluate a large set of coupling diagnostics in order to develop a hierarchical list of coupling coefficients for LoCo. These diagnostics include some of the efforts mentioned in Section 2, and will cover the range of local scale interactions from surface-PBL (e.g. mixing diagrams) to moist processes and convective triggering. LIS-WRF has recently added additional LSM options and WRF (v.3) has added another PBL scheme, both of which will be employed in this study along with a stand-alone single-column model testbed. 
Quantification of L-A interactions is particularly important for land surface data assimilation and model calibration efforts. While these are relatively young topic of research, high-quality remote sensing data (e.g. surface temperature, snow, and soil moisture) can be assimilated into LSMs using a variety of techniques and used to calibrate both land and/or atmospheric parameters. However, the impacts of these techniques are vastly different for offline and coupled models (e.g. Liu et al. 2003, 2004, 2005) due to the addition of L-A interactions and feedbacks in the latter. The mixing diagram approach can therefore be an important tool in determining the potential improvement and model sensitivity to assimilation and calibration strategies going forward.

Finally, the greater applicability of this methodology to the LoCo community is not limited to modeling studies alone. Recent advances in satellite remote sensing will continue to improve the retrieval of PBL and land surface data for a number of applications with global coverage and high temporal resolution. This includes the diurnal evolution (due to multiple sensors) of variables such as temperature and humidity (MODIS, AIRS), soil moisture (AMSR, SMOS), evaporation (MODIS, AIRS), and PBL height (AIRS, CALIPSO). As a result, the ability of satellite remote sensing to monitor the PBL and estimate L-A properties and conditions will continue to be improved and can be incorporated to the mixing diagram approach to provide insight into LoCo across the globe.

Acknowledgements. This work was supported by the NASA Energy and Water Cycle Study (NEWS; PI: Peters-Lidard) and we would like to thank NEWS, ESSIC, and GSFC for helping to make the completion of this work possible. In particular, Jim Geiger and Joe Eastman were instrumental in providing feedback and activities related to LIS-WRF. We also appreciate the 
past and ongoing collaboration with the LoCo community that has stimulated this work, in particular Bert Holtslag, Bart van den Hurk, Paul Houser, and Dara Entekhabi. 


\section{References}

Angevine W. M., 1999: Entrainment results including advection and case studies from the Flatland boundary layer experiments. J. Geophys. Res., 104, 30947-30963.

Anthes, R.A., and T.T. Warner, 1978: Development of Hydrodynamic Models Suitable for Air Pollution and Other Mesometerological Studies. Mon. Wea. Rev., 106, 1045-1078.

Barros A. P., and W. Hwu, 2002: A study of land-atmosphere interactions during summertime rainfall using a mesoscale model. J. Geophys. Res., 107, 4227, doi:10.1029/2000JD000254.

Berbery, E., Y. Luo, K. Mitchell, and A. Betts, 2003: Eta model estimated land surface processes and the hydrological cycle of the Mississippi Basin. J. Geophys. Res., 108, D22, 8852, doi:10.1029/2002JD003192.

Best, M.J., A. Beljaars, J. Polcher, and P. Viterbo, 2004: A Proposed Structure for Coupling Tiled Surfaces with the Planetary Boundary Layer. J. Hydrometeor., 5, 1271-1278.

Betts, A.K., 1984: Boundary Layer Thermodynamics of a High Plains Severe Storm. Mon. Wea. Rev., 112, 2199-2211.

—_, 1992: FIFE atmospheric boundary layer budget methods. J. Geophys. Res., 97, 1852318532.

— , 2000: Idealized model for equilibrium boundary layer over land. J. Hydrometeor., 1, 507523.

— , and J. H. Ball, 1994: Budget analysis of FIFE-1987 sonde data. J. Geophys. Res., 99, $3655-3666$.

$\longrightarrow,-$, A. C. M. Beljaars, M. J. Miller, and P.A. Viterbo, 1996: The land surfaceatmosphere interaction: A review based on observational and global modeling 
perspectives. J. Geophys. Res., 101, 7209-7226.

— , and P. Viterbo, 2005: Land-surface, boundary layer, and cloud-field coupling over the southwestern Amazon in ERA-40. J. Geophys. Res., 110, D14108, doi:10.1029/2004JD005702.

Bosilovich, M. G., J. D. Radakovich, A. da Silva, R. Todling, and F. Verter, 2007: Skin temperature analysis and bias correction in a coupled land-atmosphere data assimilation system. J. Met. Soc. Japan, 85A, 205-228.

Brubaker, K. L., and D. Entekhabi, 1996: Analysis of feedback mechanisms in land-atmosphere interaction. Water Resour. Res., 32, 1343-1357.

Chen, F., Z. Janic, and K. Mitchell, 1997a: Impact of atmospheric-surface layer parameterizations in the new land-surface scheme of the NCEP mesoscale Eta numerical model. Bound.-Layer Meteor., 85, 391-421.

Chen, T.H., A. Henderson-Sellers, P.C.D. Milly, A.J. Pitman, A.C.M. Beljaars, J. Polcher, F. Abramopoulos, A. Boone, S. Chang, F. Chen, Y. Dai, C.E. Desborough, R.E. Dickinson, L. Dümenil, M. Ek, J.R. Garratt, N. Gedney, Y.M. Gusev, J. Kim, R. Koster, E.A. Kowalczyk, K. Laval, J. Lean, D. Lettenmaier, X. Liang, J.F. Mahfouf, H.T. Mengelkamp, K. Mitchell, O.N. Nasonova, J. Noilhan, A. Robock, C. Rosenzweig, J. Schaake, C.A. Schlosser, J.P. Schulz, Y. Shao, A.B. Shmakin, D.L. Verseghy, P. Wetzel, E.F. Wood, Y. Xue, Z.L. Yang, and Q. Zeng, 1997b: Cabauw Experimental Results from the Project for Intercomparison of Land-Surface Parameterization Schemes. J. Climate, 10, 1194-1215.

Cheng, W.Y.Y., and W.J. Steenburgh, 2005: Evaluation of Surface Sensible Weather Forecasts by the WRF and the Eta Models over the Western United States. Wea. Forecasting, 20, 
$812-821$.

Cleugh H. A., M. R. Raupach, P. R. Briggs, and P. A. Coppin, 2004: Regional-scale heat and water vapour fluxes in an agricultural landscape: An evaluation of CBL budget methods at OASIS. Bound.-Layer Meteorol., 110, 99-137.

Dai Y. J., Coauthors, 2003: The Common Land Model. Bull. Amer. Meteor. Soc, 84, 10131023.

Desai, A. R., Davis, K. J., Senff, C. J., Ismail, S., Browell, E. V., Stauffer, D. R., and Reen, B. P.: 2006: A Case Study on the Effects of Heterogeneous Soil Moisture on Mesoscale Boundary Layer Structure in the Southern Great Plains, U.S.A. Part I: Simple Prognostic Model. Bound.-Layer Meteorol., 119, DOI: 10.1007/s10546-005-9024-6.

Diak G. R., 1990: Evaluation of heat flux, moisture flux and aerodynamic roughness at the land surface from knowledge of the PBL height and satellite derived skin temperatures. Agric. For. Meteor., 22, 505-508.

Dirmeyer, P. A., A. J. Dolman, and N. Sato, 1999: The Global Soil Wetness Project: A pilot project for global land surface modeling and validation. Bull. Amer. Meteor. Soc., 80, 851-878.

Dirmeyer P. A., Z. Guo, and X. Gao, 2004: Comparison, validation, and transferability of eight multiyear global soil wetness products. J. Hydrometeor., 5, 1011-1033.

Dolman A., J. Gash, J. Goutorbé, Y. Kerr, T. Lebel, S. Prince, and J. Stricker, 1997: The role of the land surface in Sahelian climate: HAPEX-Sahel results and future research needs. $J$. Hydrol, 188/189, 1067-1079.

Ek M. B., and A. A. M. Holtslag, 2004: Influence of soil moisture on boundary layer cloud development. J. Hydrometeor., 5, 86-99. 
Ek M. B., K. E. Mitchell, Y. Lin, E. Rogers, P. Grunmann, V. Koren, G. Gayno, and J. D. Tarpley, 2003: Implementation of Noah land surface model advances in the National Centers for Environmental Prediction operational mesoscale Eta Model. J. Geophys. Res., 108, 8851, doi:10.1029/2002JD003296.

Eltahir E. A., 1998: A soil moisture-rainfall feedback mechanism: 1. Theory and observations. Water Resour. Res., 34, 765-776.

Entekhabi, D., and K. L. Brubaker, 1995: An analytic approach to modeling land-atmosphere interaction. 2: Stochastic extension. Water Resour. Res., 31, 633-643.

Entekhabi D., Coauthors, 1999: An agenda for land surface hydrology research and a call for the second international hydrology decade. Bull. Amer. Meteor. Soc., 80, 2043-2058.

Findell K. L., and E. A. Eltahir, 2003a: Atmospheric controls on soil moisture-boundary layer interactions: Three-dimensional wind effects. J. Geophys. Res., 108, 8385, doi:10.1029/2001JD001515.

Findell K. L., and E. A. Eltahir, 2003b: Atmospheric controls on soil moisture-boundary layer interactions. Part I: Framework development. J. Hydrometeor., 4, 552-569.

Garratt, J. R., 1992: The Atmospheric Boundary Layer. Cambridge University Press, 316 pp..

Gu, L., T. Meyers, S. G. Pallardy, P. J. Hanson, B. Yang, M. Heuer, K. P. Hosman, J. S. Riggs, D. Sluss, and S. D. Wullschleger, 2006: Direct and indirect effects of atmospheric conditions and soil moisture on surface energy partitioning revealed by a prolonged drought at a temperate forest site, J. Geophys. Res., 111, D16102, doi:10.1029/2006JD007161.

Hacker, J.P., and D. Rostkier-Edelstein, 2007: PBL State Estimation with Surface Observations, a Column Model, and an Ensemble Filter. Mon. Wea. Rev., 135, 2958-2972. 
Hacker, J.P., and C. Snyder, 2005: Ensemble Kalman Filter Assimilation of Fixed Screen-Height Observations in a Parameterized PBL. Mon. Wea. Rev., 133, 3260-3275.

Henderson-Sellers, A., Z.L. Yang, and R. Dickinson, 1993: The Project for Intercomparison of Land-surface Parameterization Schemes. Bull. Amer. Meteor. Soc., 74, 1335-1349.

Hess R., 2001: Assimilation of screen-level observations by variational soil moisture. Meteor. Atmos. Phys., 77, 145-154.

Hogue, T. S., L. Bastidas, H. Gupta, S. Sorooshian, K. Mitchell, and W. Emmerich, 2005:

Evaluation and Transferability of the Noah Land Surface Model in Semiarid Environments. J. Hydrometeorol., 6, 68-84.

Holt, T. R., D. Niyogi, F. Chen, K. Manning, and M. A. LeMone, and A. Qureshi, 2006: Effect of land-atmosphere interactions on the IHOP 24-25 May 2002 convection case. Mon. Wea. Rev., 134, 113-133.

Holtslag, A. A. M., G. J. Steeneveld, and B. J. H. van de Wiel, 2007: Role of land-surface temperature feedback on model performance for the stable boundary layer. Bound.-Layer Meteorol, 125, 361-376.

Hong, S.Y., and H.L. Pan, 1996: Nonlocal Boundary Layer Vertical Diffusion in a MediumRange Forecast Model. Mon. Wea. Rev., 124, 2322-2339.

Hong, S.Y., Y. Noh, and J. Dudhia, 2006: A New Vertical Diffusion Package with an Explicit Treatment of Entrainment Processes. Mon. Wea. Rev., 134, 2318-2341.

Jacobs, C., and H. De Bruin, 1992: The Sensitivity of Regional Transpiration to Land-Surface Characteristics: Significance of Feedback. J. Climate, 5, 683-698.

Janjic, Z. I., 2001: Nonsingular implementation of the Mellor-Yamada level 2.5 scheme in the NCEP meso model. Technical Report 437, National Centers for Environmental Prediction Office. 
Kim C. P., and D. Entekhabi, 1998: Feedbacks in the land-surface and mixed-layer energy budgets. Bound.-Layer Meteor., 88, 1-21.

Koster R. D., P. A. Dirmeyer, A. N. Hahmann, R. Ijpelaar, L. Tyahla, P. Cox, and M. J. Suarez, 2002: Comparing the degree of land-atmosphere interaction in four atmospheric general circulation models. J. Hydrometeor, 3, 363-375.

Koster R. D., Coauthors, 2004: Regions of strong coupling between soil moisture and precipitation. Nature, 306, 1138-1140.

Kumar, S. V., C. D. Peters-Lidard, J. L. Eastman, and W.-K. Tao, 2008: An integrated high resolution hydrometeorological modeling testbed using LIS and WRF. Environmental Modelling and Software, 23, 169-181.

Kustas W. P., and W. Brutsaert, 1987: Virtual heat entrainment in the mixed layer over very rough terrain. Bound.-Layer Meteor., 38, 141-157.

Lawrence, D.M., and J.M. Slingo, 2005: Weak Land-Atmosphere Coupling Strength in HadAM3: The Role of Soil Moisture Variability. J. Hydrometeor., 6, 670-680.

Liu, Y., L. A. Bastidas, H. V. Gupta, and S. Sorooshian, 2003: Impacts of a Parameterization Deficiency on Offline and Coupled Land Surface Model Simulations. J. Hydrometeorol., 4, 901-914.

Liu, Y., H. V. Gupta, S. Sorooshian, L. A. Bastidas, and W. J. Shuttleworth, 2004: Exploring Parameter Sensitivities of the Land Surface Using a Locally Coupled Land-Atmosphere Model. J. Geophys. Res., 109, 21101-21114.

Liu, Y., H. V. Gupta, S. Sorooshian, L. A. Bastidas, and W. J. Shuttleworth, 2005: Constraining Land Surface and Atmospheric Parameters of a Locally Coupled Model Using Observational Data. J. Hydrometeorol., 6, 156-172. 
Margulis, S. A., and D. Entekhabi, 2001: Feedback between the Land Surface Energy Balance and Atmospheric Boundary Layer Diagnosed through a Model and its Adjoint. $J$. Hydrometeorol., 2, 599-620.

Medeiros, B., A. Hall, and B. Stevens, 2005: What Controls the Mean Depth of the PBL? J. Climate, 18, 3157-3172.

Mellor, G. L., and T. Yamada, 1982: Development of a turbulence closure model for geophysical fluid problems. Rev. Geophys. Space Phys., 20, 851-875.

Mesinger, F., G. DiMego, E. Kalnay, K. Mitchell, P.C. Shafran, W. Ebisuzaki, D. Jović, J. Woollen, E. Rogers, E.H. Berbery, M.B. Ek, Y. Fan, R. Grumbine, W. Higgins, H. Li, Y. Lin, G. Manikin, D. Parrish, and W. Shi, 2006: North American Regional Reanalysis. Bull. Amer. Meteor. Soc., 87, 343-360.

Michalakes, J., S. Chen, J. Dudhia, L. Hart, J. Klemp, J. Middlecoff, and W. Skamarock, 2001: Development of a next generation regional weather research and forecast model. Developments in Teracomputing: Proceedings of the Ninth ECMWF Workshop on the use of high performance computing in meteorology. Singapore, pp. 269-276.

Molod, A., H. Salmun, and D.W. Waugh, 2004: The Impact on a GCM Climate of an Extended Mosaic Technique for the Land-Atmosphere Coupling. J. Climate, 17, 3877-3891.

Oke T. R., 1987: Boundary Layer Climates. 2d ed. Routledge, 435 pp.

Pan, H.-L., and L. Mahrt, 1987: Interaction between soil hydrology and boundary-layer development. Bound.-Layer Meteor., 38, 185-202..

Peters-Lidard C., and L. H. Davis, 2000: Regional flux estimation in a convective boundary layer using a conservation approach. J. Hydrometeor, 1, 170-182.

Pitman A. J., Coauthors, 1999: Key results and implications from phase 1(c) of the Project for 
Intercomparison of Land-surface Parameterization Schemes. Climate Dyn., 15, 673-684.

Polcher J., Coauthors, 1998: A proposal for a general interface between land-surface schemes and general circulation models. Global Planet. Change, 19, 261-276.

Reen, B. P., D. R. Stauffer, K. J. David, and A. Desai, 2006: A Case Study on the Effects of Heterogeneous Soil Moisture on Mesoscale Boundary Layer Structure in the Southern Great Plains, U.S.A. Part II: Mesoscale Modeling. Bound.-Layer Meteorol., 120, DOI: 10.1007/s10546-006-9056-6.

Reichle, R. H., R. D. Koster, P. Liu, S. P. P. Mahanama, E. G. Njoku, and M. Owe, 2007: Comparison and assimilation of global soil moisture retrievals from the Advanced Microwave Scanning Radiometer for the Earth Observing System (AMSR-E) and the Scanning Multichannel Microwave Radiometer (SMMR). J. Geophys. Res., 112, D09108.

Rhodin A., F. Kucharski, U. Callies, D. P. Eppel, and W. Wergen, 1999: Variational analysis of effective soil moisture from screen-level atmospheric parameters: Application to a shortrange weather forecast model. Quart. J. Roy. Meteor. Soc., 125, 2427-2448.

Rodell, M. and P. R. Houser, 2004: Updating a land surface model with MODIS-derived snow cover. Journal of Hydrometeorology, 5, 1064-1075.

Santanello, J. A., M. A. Friedl, and M. Ek, 2007: Convective Planetary Boundary Layer Interactions with the Land Surface at Diurnal Time Scales: Diagnostics and Feedbacks. J. Hydrometeor., 8, 1082-1097.

Santanello, J. A., M. A. Friedl, and W. P. Kustas, 2005: Empirical Investigation of Convective Planetary Boundary Layer Evolution and its Relationship with Land Surface Properties and Processes. J Appl. Meteorol., 44, 917-932. 
Seuffert G., H. Wilker, P. Viterbo, M. Drusch, and J. F. Mahfouf, 2004: The usage of screenlevel parameters and microwave brightness temperature for soil moisture analysis. $J$. Hydrometeor, 5, 516-531.Sorbjan 1995

Sorbjan, Z., 1995: Toward evaluation of heat fluxes in the convective boundary layer. J. Appl. Meteorol., 34, 1092-1098.

Steeneveld, G.J., B.J.H. van de Wiel, and A.A.M. Holtslag, 2006: Modeling the Evolution of the Atmospheric Boundary Layer Coupled to the Land Surface for Three Contrasting Nights in CASES-99. J. Atmos. Sci., 63, 920-935.

Stensrud, D. J., 2007: Parameterization Schemes: Keys to Understanding Numerical Weather Prediction Models. Cambridge University Press, 459 pp.

Stull, R. B., 1988: An Introduction to Boundary Layer Meteorology. Kluwer Academic, 666 pp.

Trier, S. B., F. Chen, and K. W. Manning, 2004: A study of convection initiation in a mesoscale model using high-resolution land surface initial conditions. Mon. Wea. Rev., 132, 29542976.

Troen, I., and L. Mahrt, 1986: A simple model of the atmospheric boundary layer: Sensitivity to surface evaporation. Bound.-Layer Meteor., 37, 129-148..

van den Hurk, B., A. Holtslag, and C. D. Peters-Lidard, 20005: GLASS and GABLS workshop on local land-atmosphere coupling - 19/21 Sep. 2005: Workshop Summary and LoCo Implementation Plan.

Weckworth T. M., Coauthors, 2004: An overview of the International $\mathrm{H}_{2} \mathrm{O}$ Project (IHOP_2002) and some preliminary highlights. Bull. Amer. Meteor. Soc, 85, 253-277. 


\section{List of Figures}

Figure 1: a) Diurnal evolution (12-00Z; solid line) of $2 \mathrm{~m}$-potential temperature $\left(C_{p} \theta\right)$ vs. $2 \mathrm{~m}$ specific humidity $(L q)$ from a representative day during June 2002 in the U.S. Southern Great Plains as simulated by a coupled mesoscale model. The annotations on the plots depict the vector component contributions of surface and entrainment fluxes that are obtained using the mixing diagram approach. b) 12-hour time series of $2 \mathrm{~m}$-potential temperature $(\theta)$ and $2 \mathrm{~m}$ specific humidity $(q)$ corresponding to Fig. 1a. c) 12-hour time series of PBL height $(P B L H)$ and surface sensible heat flux $\left(H_{s f c}\right)$ which are used in calculating the vector and flux components in Fig. 1a.

Figure 2: Soil moisture (volumetric: $\left.\mathrm{m}^{3} \mathrm{~m}^{-3}\right)$ in the upper $(0-10 \mathrm{~cm})$ layer valid at $12 \mathrm{Z}$ on 12 June 2002 as simulated from a 2.5 year spinup of the Noah model over the 1-km LIS-WRF domain in the SGP for the IHOP-02 experiment. The ARM-SGP Central Facility (CF) at Lamont, $\mathrm{OK}$ is also shown along with the dry, intermediate, and wet soil locations presented in Figs. 3-5.

Figure 3: Diurnal co-evolution (12-00Z) of $2 \mathrm{~m}$-specific humidity $(L q)$ and $2 \mathrm{~m}$-potential temperature $\left(C_{p} \theta\right)$ on 12 June 2002 as simulated by LIS-WRF during dry soil moisture conditions [a) 0.11 , b) $0.08 \mathrm{~m}^{3} \mathrm{~m}^{-3}$ ] in the Southern Great Plains using the a) Noah and b) CLM LSMs with the YSU (red solid), and MYJ (green solid), and MRF (blue solid) PBL schemes. Also shown are the surface $\left(\mathbf{V}_{\text {sfe }}\right)$ and entrainment $\left(\mathbf{V}_{\text {ent }}\right)$ vectors (dashed lines), surface $\left(\beta_{s f c}\right)$ and entrainment $\left(\beta_{\text {ent }}\right)$ Bowen ratio values, and heat $\left(A_{h}\right)$ and moisture $\left(A_{l e}\right)$ entrainment ratios.

Figure 4: Same as Figure 3, but for intermediate soil moisture conditions $\left[0.18 \mathrm{~m}^{3} \mathrm{~m}^{-3}\right]$.

Figure 5: Same as Figure 3, but for wet soil moisture conditions [a) 0.32 and b) $0.40 \mathrm{~m}^{3} \mathrm{~m}^{-3}$ ]. 
Figure 6: Relationship between latent $(L E)$ and sensible $(H)$ heat fluxes from the surface ( $\mathbf{m})$, entrainment $(\boldsymbol{\Delta})$, and their sums $(\diamond)$ as simulated by LIS-WRF using the six PBL-LSM combinations for dry, intermediate, and wet soil conditions and derived using the mixing diagrams in Figs. 3-5 and values given in Table 1. The dashed lines represent a theoretical constant surface $(H+L E)$ net radiation of $500 \mathrm{Wm}^{-2}$ for comparison with the simulations.

Figure 7: Relationship of evaporative fraction $\left(L E_{s f c} /\left(L E_{s f c}+H_{s f c}\right)\right)$ to maximum PBL height as simulated by the Noah (०) and CLM (•) LSMs coupled with the YSU (red), MYJ (green), and MRF (blue) PBL schemes in LIS-WRF on June 12 at the dry, intermediate, and wet soil locations shown in Figs. 3-5.

Figure 8: Diurnal co-evolution (12-00Z) of 2m-specific humidity $(L q)$ and 2m-potential temperature $\left(C_{p} \theta\right)$ on 6 June 2002 as simulated by LIS-WRF for the ARM-SGP CF at Lamont, OK using the a) Noah and b) CLM models and PBL combinations with the associated surface and entrainment vectors and derived metrics. Also overlain are observations from CF and metrics calculated from surface meteorology, flux, and profile measurements (black).

Figure 9: Same as Figure 8 for the ARM-SGP Extended Facility at Plevna, KS.

Figure 10: Same as Fig. 6, but for the a) E13 and b) E4 sites on 6 June 2002 (Figs. 8 and 9) along with observations (open black). The dashed line represents values of constant available energy $\left(H_{s f c}+L E_{s f c}\right)$ equal to that observed.

Figure 11: Relationship of evaporative fraction $\left(L E_{s f c} /\left(L E_{s f c}+H_{s f c}\right)\right)$ to maximum PBL height as simulated by the Noah (०) and CLM (•) LSMs coupled with the YSU (red), MYJ (green), and MRF (blue) PBL schemes in LIS-WRF on June 6 at the E13 and E4 sites shown in Figs. 8 and 9. Figure 12: Diurnal evolution (12-00Z; solid line) of $2 \mathrm{~m}$-potential temperature $\left(C_{p} \theta\right)$ vs. $2 \mathrm{~m}$ specific humidity $(L q)$ from a representative day during June 2002 in the U.S. Southern Great 
Plains. The annotations on the plots depict the vector component contributions of surface and entrainment fluxes, and the addition of a vector due to the horizontal advection of heat and moisture $\left(\mathbf{V}_{\text {adv }}\right)$.

Figure 13: Mixing diagrams generated from LIS-WRF simulations using Noah and CLM for wet soil moisture conditions (see Fig. 5) with the addition of the horizontal advection vector $\left(\mathbf{V}_{\text {adv }}\right)$ and Bowen ratio $\left(\beta_{a d v}\right)$. The arrows indicate the direction of the advective fluxes.

Figure 14: Total mean fluxes of heat $\left(H_{t o t}\right)$ and moisture $\left(L E_{t o t}\right)$ and their component fluxes from the land surface $\left(H_{s f c}, L E_{s f c}\right)$, advection $\left(H_{a d v}, L E_{a d v}\right)$, and entrainment $\left(H_{e n t}, L E_{\text {ent }}\right)$ derived from the a) Noah and b) CLM mixing diagrams both without (from Fig. 5) and with (Fig. 13) advection, and c) plotted with advection as in Fig. 6c. 

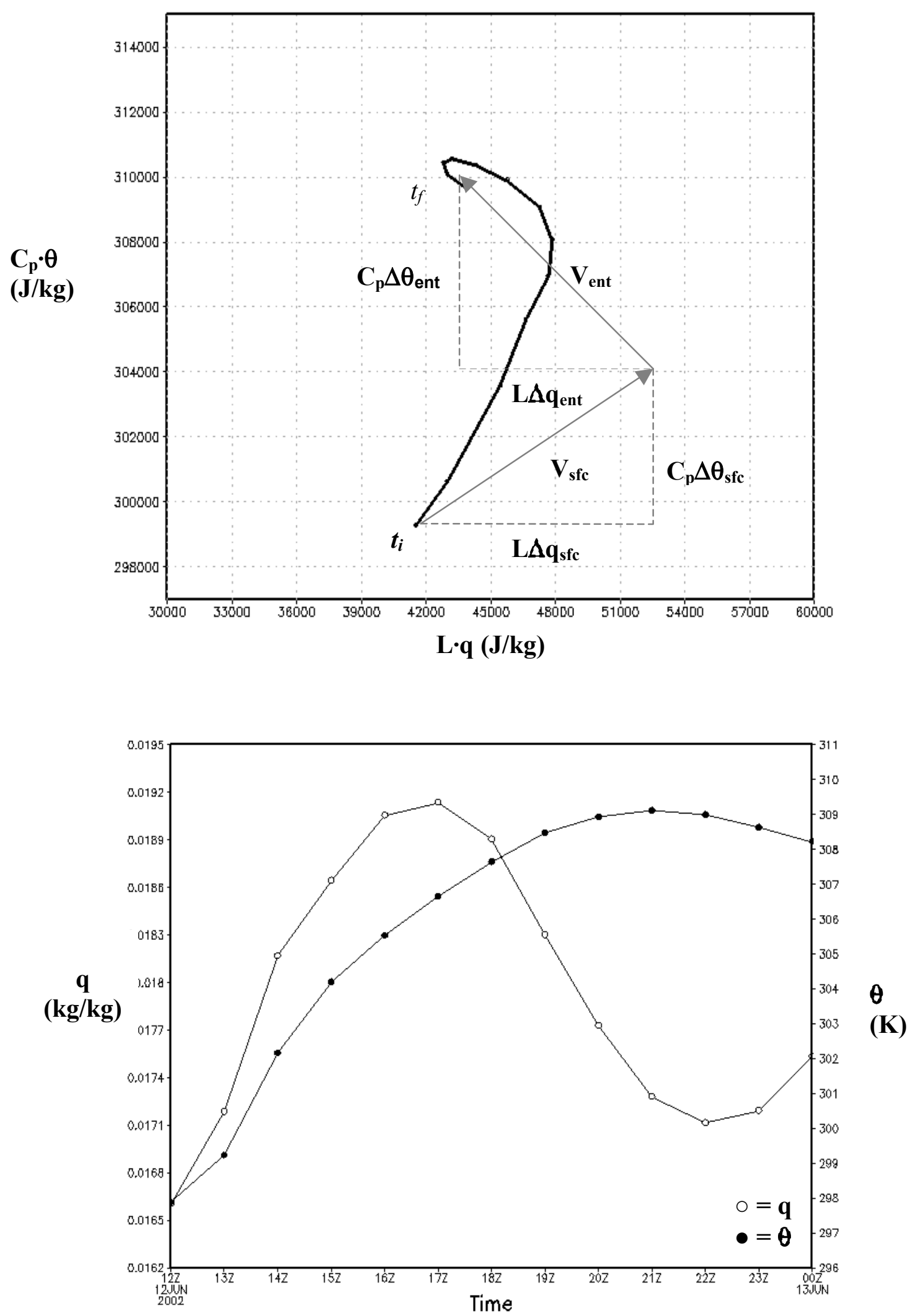


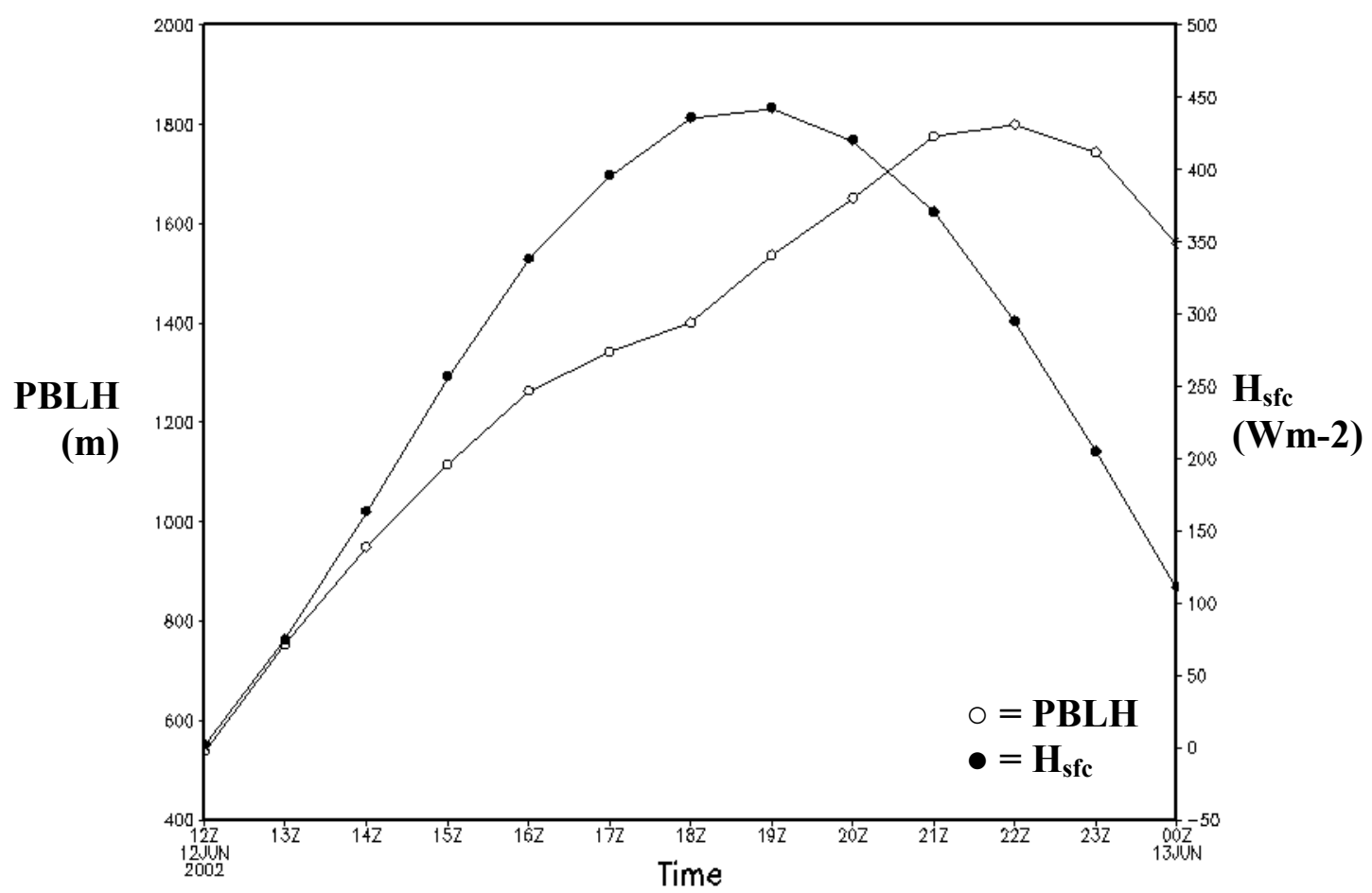

Figure 1: a) Diurnal evolution (12-00Z; solid line) of $2 \mathrm{~m}$-potential temperature $\left(C_{p} \theta\right)$ vs. $2 \mathrm{~m}$ specific humidity $(L q)$ from a representative day during June 2002 in the U.S. Southern Great Plains as simulated by a coupled mesoscale model. The annotations on the plots depict the vector component contributions of surface and entrainment fluxes that are obtained using the mixing diagram approach. b) 12-hour time series of $2 \mathrm{~m}$ potential temperature $(\theta)$ and $2 \mathrm{~m}$ specific humidity $(q)$ corresponding to Fig. 1a. c) 12-hour time series of PBL height $(P B L H)$ and surface sensible heat flux $\left(H_{s f c}\right)$ which are used in calculating the vector and flux components in Fig. 1a. 


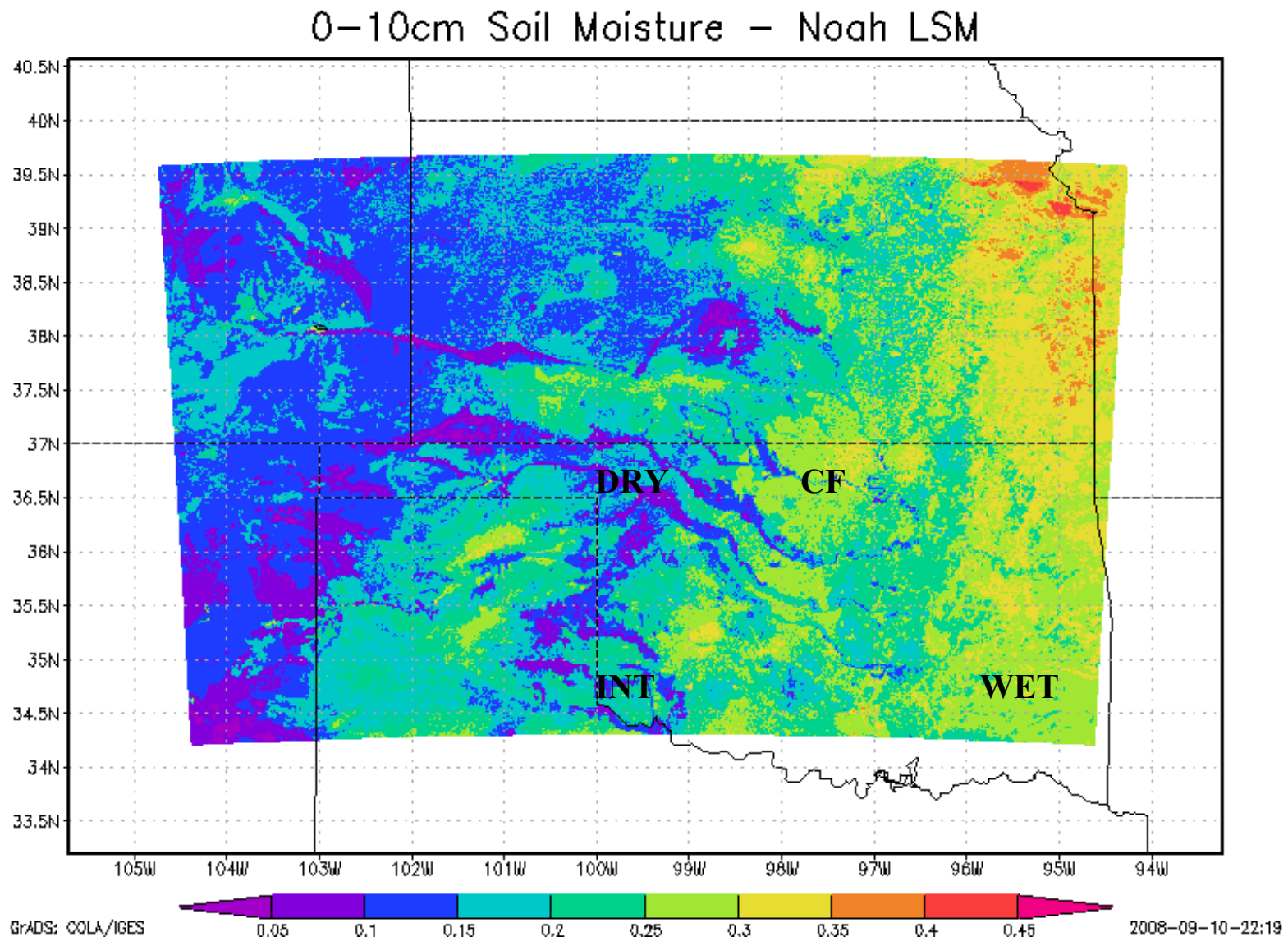

Figure 2: Soil moisture (volumetric: $\left.\mathrm{m}^{3} \mathrm{~m}^{-3}\right)$ in the upper $(0-10 \mathrm{~cm})$ layer valid at $12 \mathrm{Z}$ on 12 June 2002 as simulated from a 2.5 year spinup of the Noah model over the 1-km LIS-WRF domain in the SGP for the IHOP-02 experiment. The ARM-SGP Central Facility (CF) at Lamont, $\mathrm{OK}$ is also shown along with the dry, intermediate, and wet soil locations presented in Figs. 3-5. 

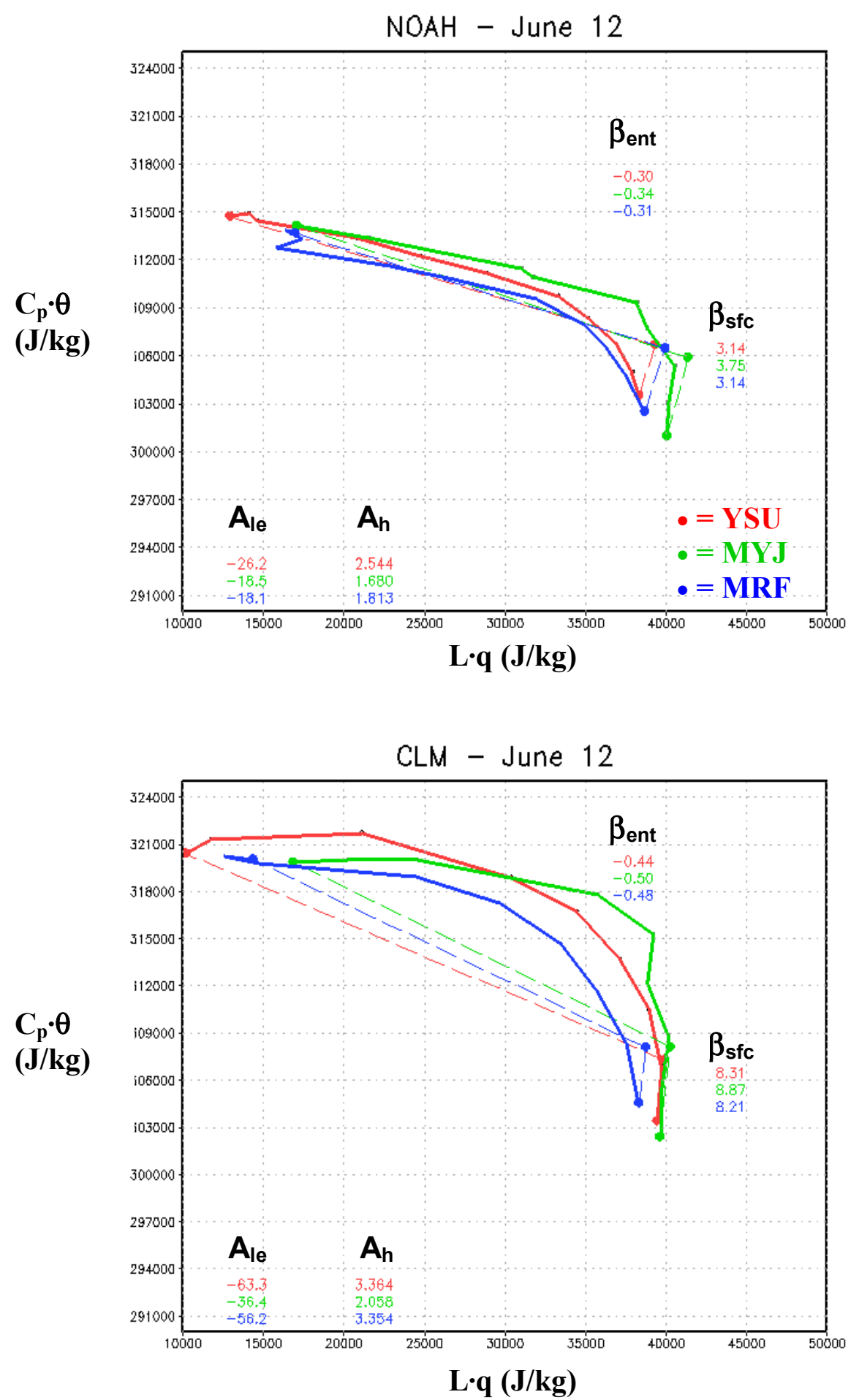

Figure 3: Diurnal co-evolution (12-00Z) of $2 \mathrm{~m}$-specific humidity $(L q)$ and 2 m-potential temperature $\left(C_{p} \theta\right)$ on 12 June 2002 as simulated by LIS-WRF during dry soil moisture conditions [a) 0.11 , b) $0.08 \mathrm{~m}^{3} \mathrm{~m}^{-3}$ ] in the Southern Great Plains using the a) Noah and b) CLM LSMs with the YSU (red solid), and MYJ (green solid), and MRF (blue solid) PBL schemes. Also shown are the surface $\left(\mathbf{V}_{\text {sfc }}\right)$ and entrainment $\left(\mathbf{V}_{\text {ent }}\right)$ vectors (dashed lines), surface $\left(\beta_{\text {sfc }}\right)$ and entrainment $\left(\beta_{\text {ent }}\right)$ Bowen ratio values, and heat $\left(A_{h}\right)$ and moisture $\left(A_{l e}\right)$ entrainment ratios. 

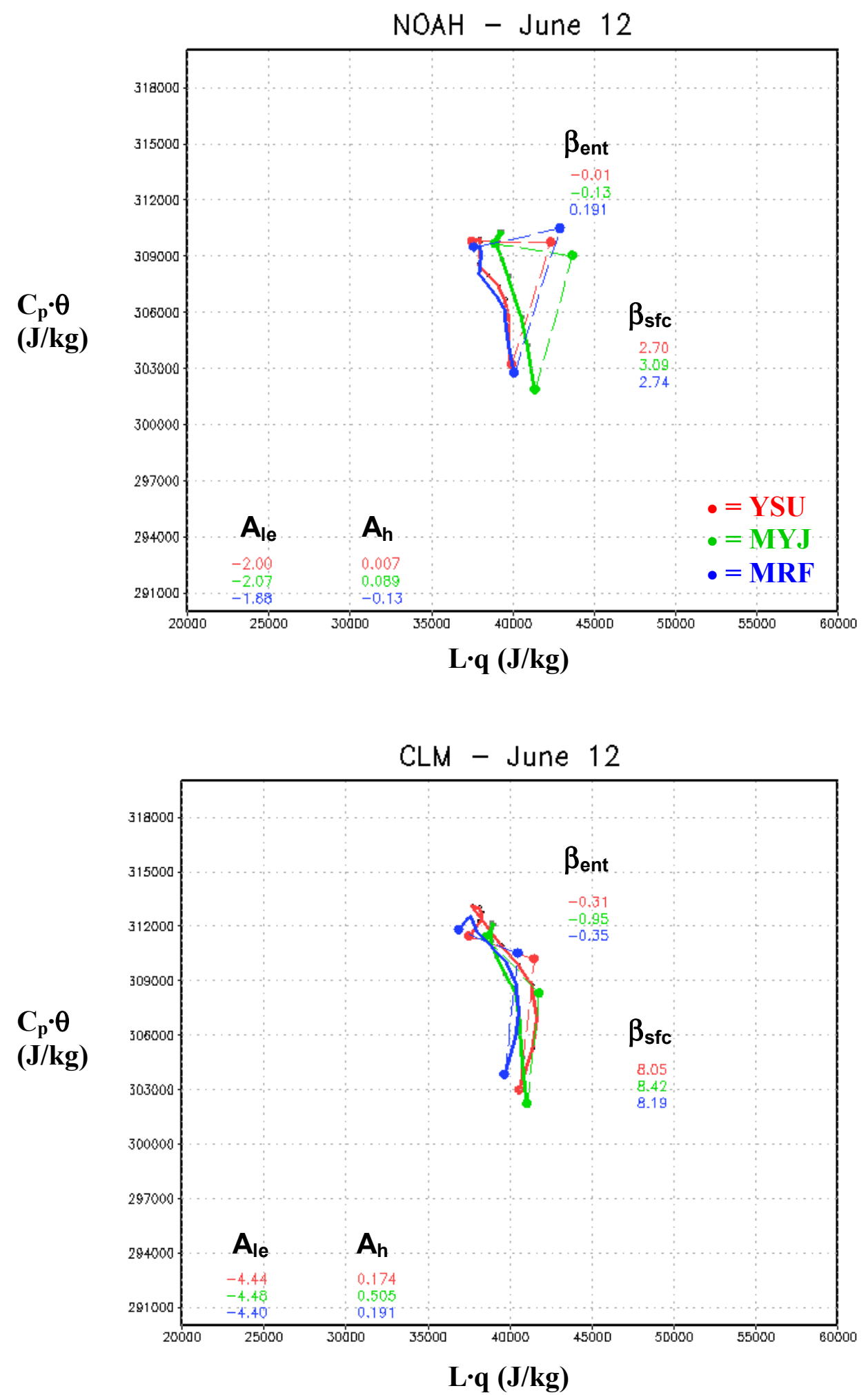

Figure 4: Same as Figure 3, but for intermediate soil moisture conditions $\left[0.18 \mathrm{~m}^{3} \mathrm{~m}^{-3}\right]$. 

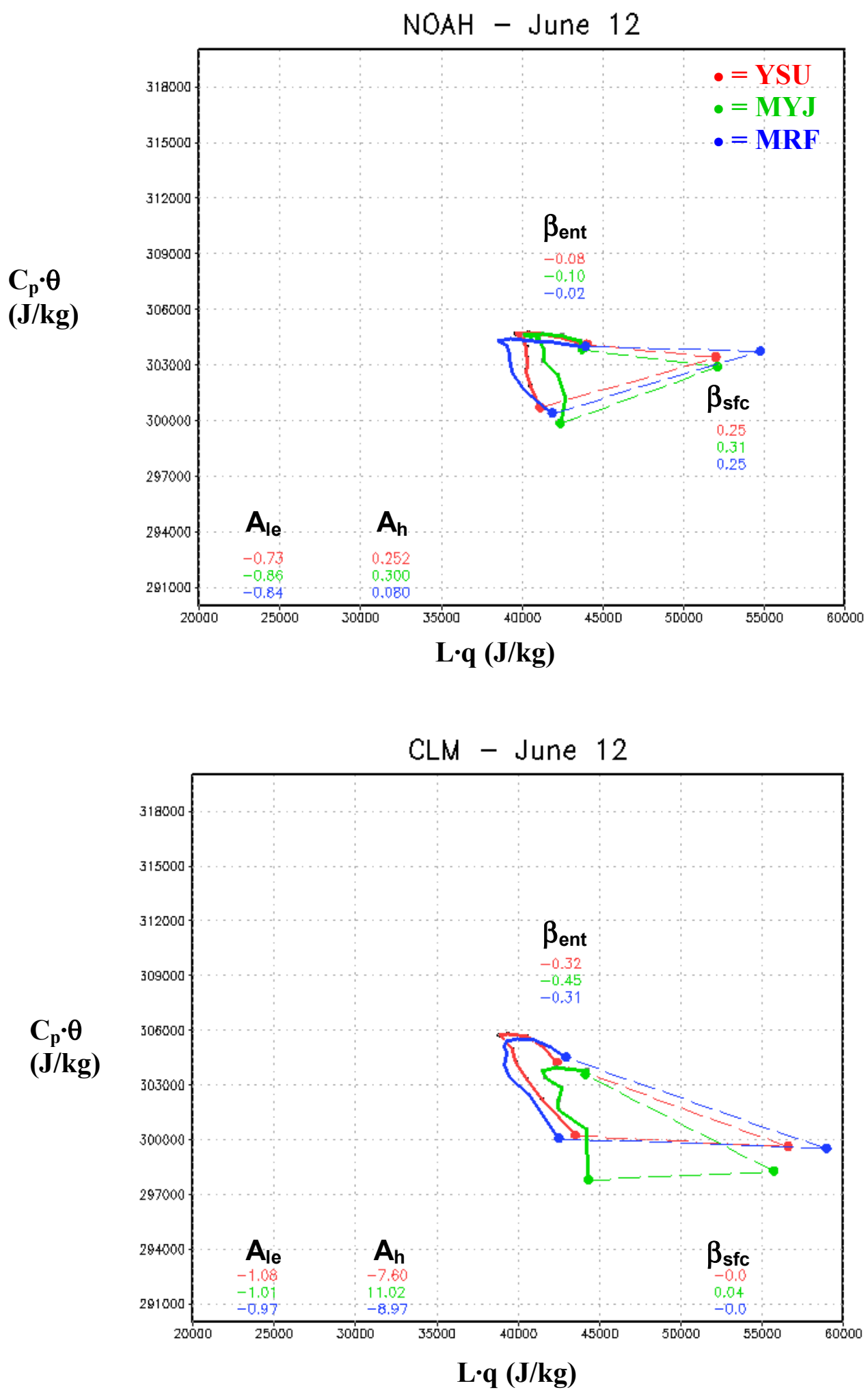

Figure 5: Same as Figure 3, but for wet soil moisture conditions [a) 0.32 and b) $0.40 \mathrm{~m}^{3} \mathrm{~m}^{-3}$ ]. 

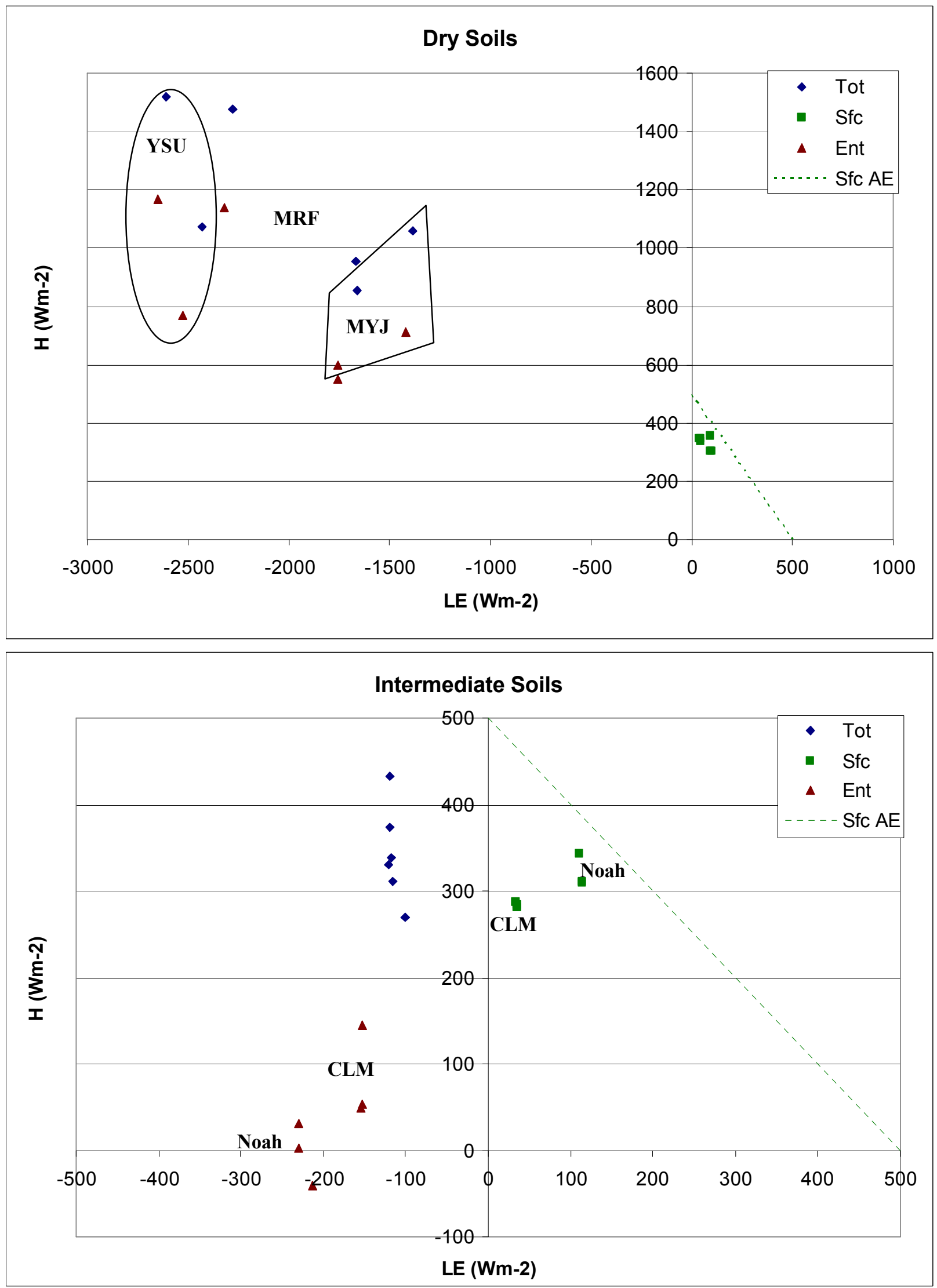


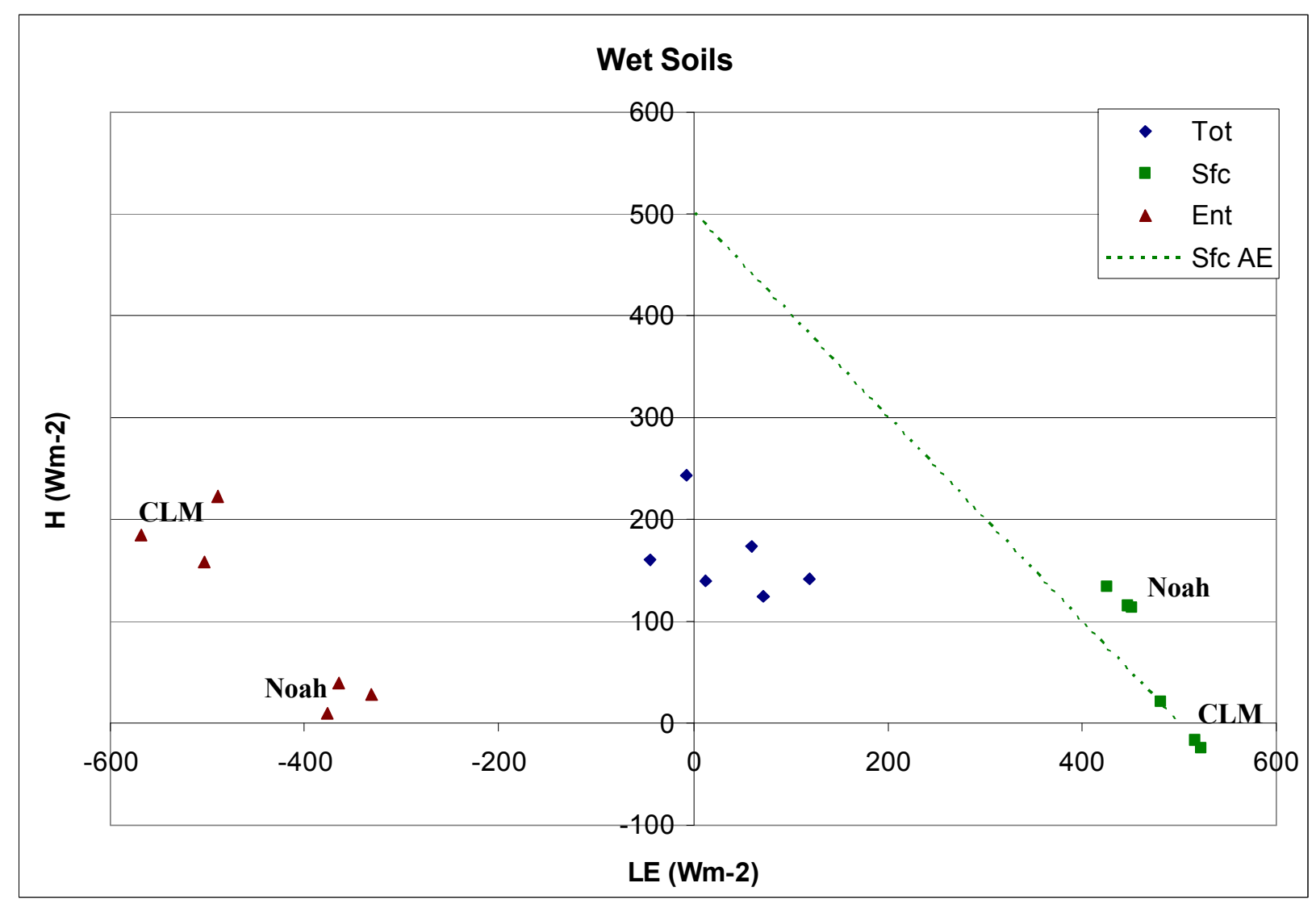

Figure 6: Relationship between latent $(L E)$ and sensible $(H)$ heat fluxes from the surface ( $\mathbf{(})$, entrainment $(\boldsymbol{\Delta})$, and their sums $(\diamond)$ as simulated by LIS-WRF using the six PBL-LSM combinations for dry, intermediate, and wet soil conditions and derived using the mixing diagrams in Figs. 3-5 and values given in Table 1. The dashed lines represent a theoretical constant surface $(H+L E)$ net radiation of $500 \mathrm{Wm}^{-2}$ for comparison with the simulations. 


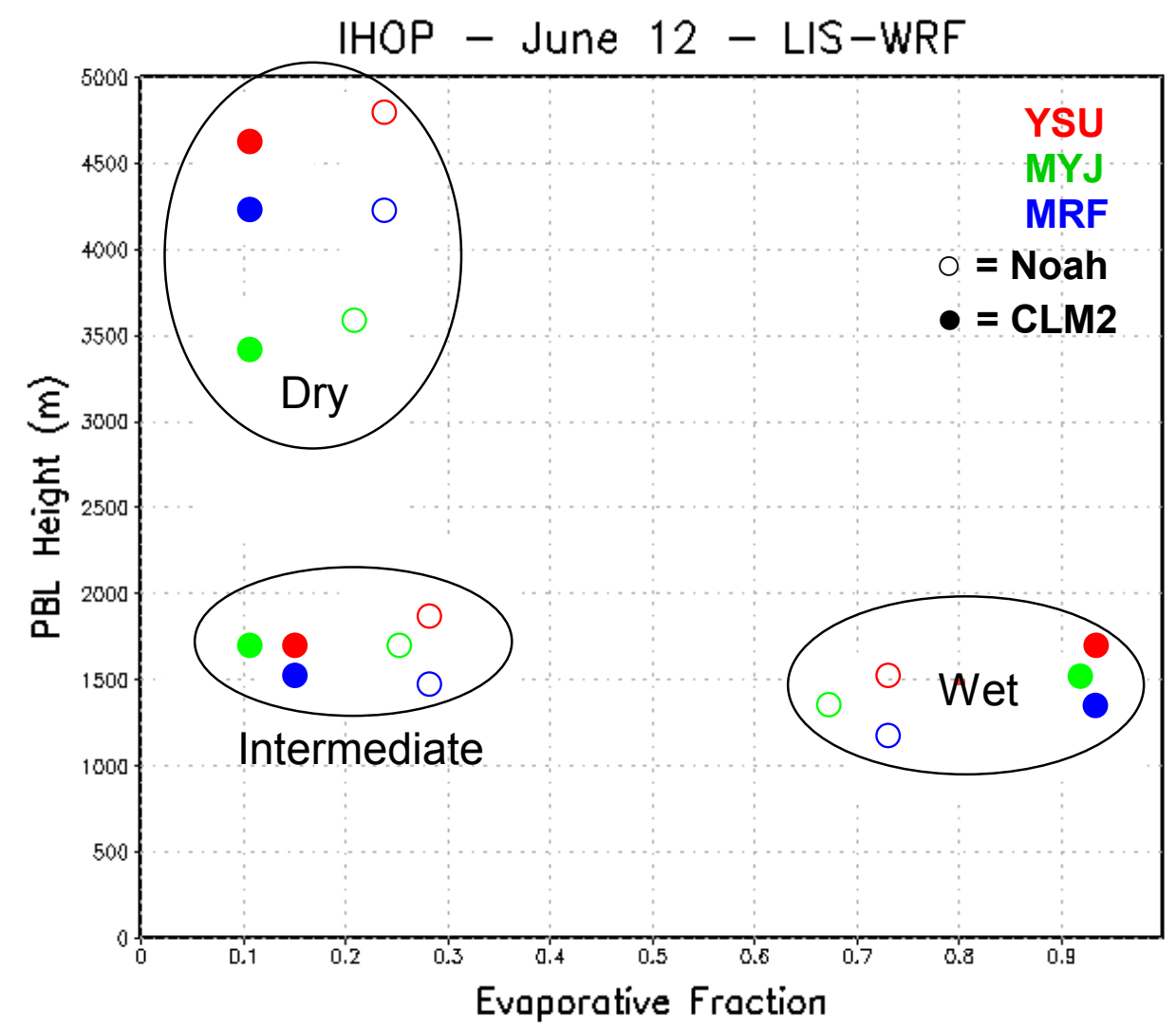

Figure 7: Relationship of evaporative fraction $\left(L E_{s f c} /\left(L E_{s f c}+H_{s f c}\right)\right)$ to maximum PBL height as simulated by the Noah (O) and CLM (•) LSMs coupled with the YSU (red), MYJ (green), and MRF (blue) PBL schemes in LIS-WRF on June 12 at the dry, intermediate, and wet soil locations shown in Figs. 3-5. 

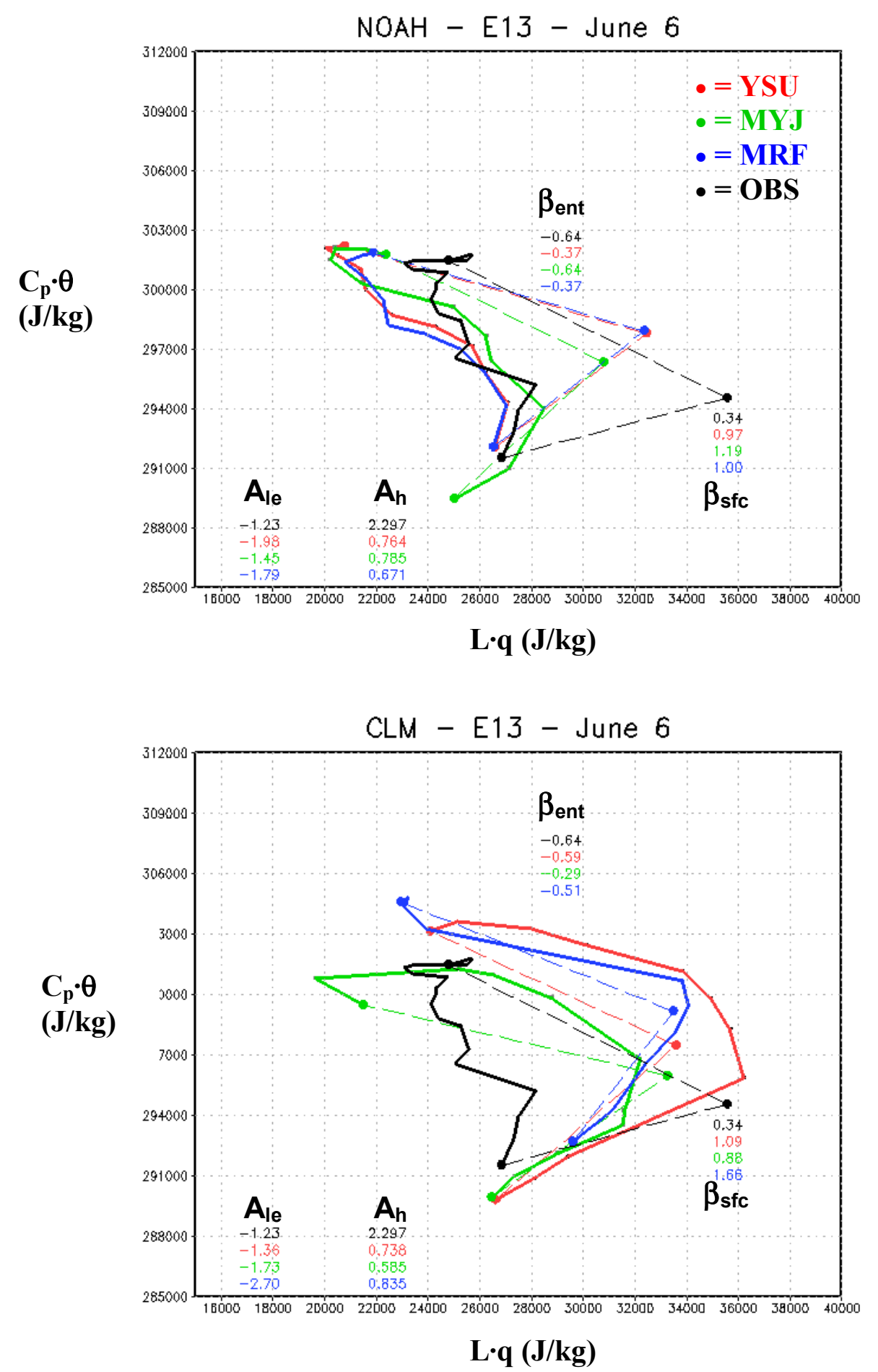

Figure 8: Diurnal co-evolution (12-00Z) of 2m-specific humidity $(L q)$ and 2m-potential temperature $\left(C_{p} \theta\right)$ on 6 June 2002 as simulated by LIS-WRF for the ARM-SGP CF at Lamont, OK using the a) Noah and b) CLM models and PBL combinations with the associated surface and entrainment vectors and derived metrics. Also overlain are observations from $\mathrm{CF}$ and metrics calculated from surface meteorology, flux, and profile measurements (black). 

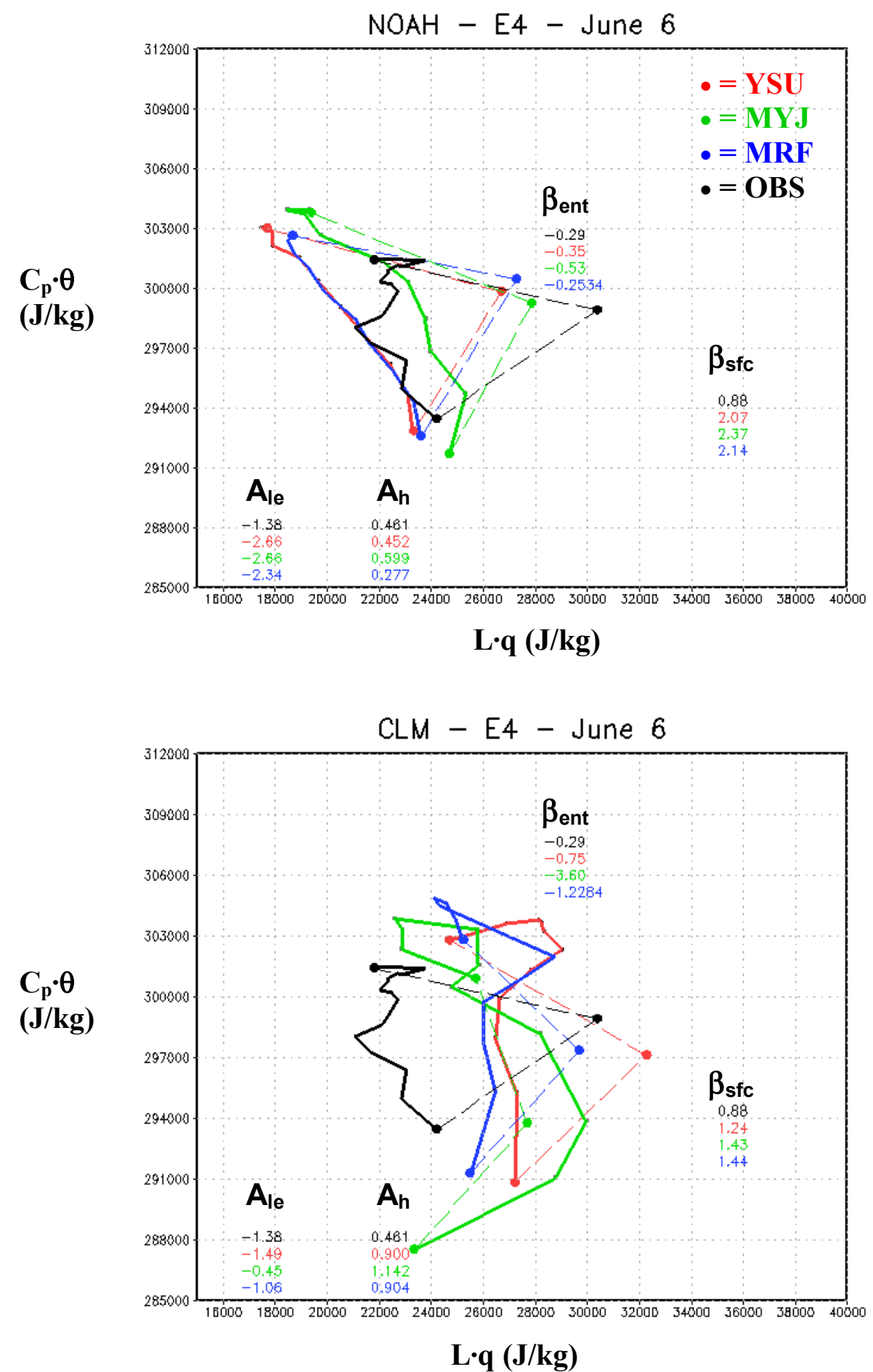

Figure 9: Same as Figure 8 for the ARM-SGP Extended Facility at Plevna, KS. 

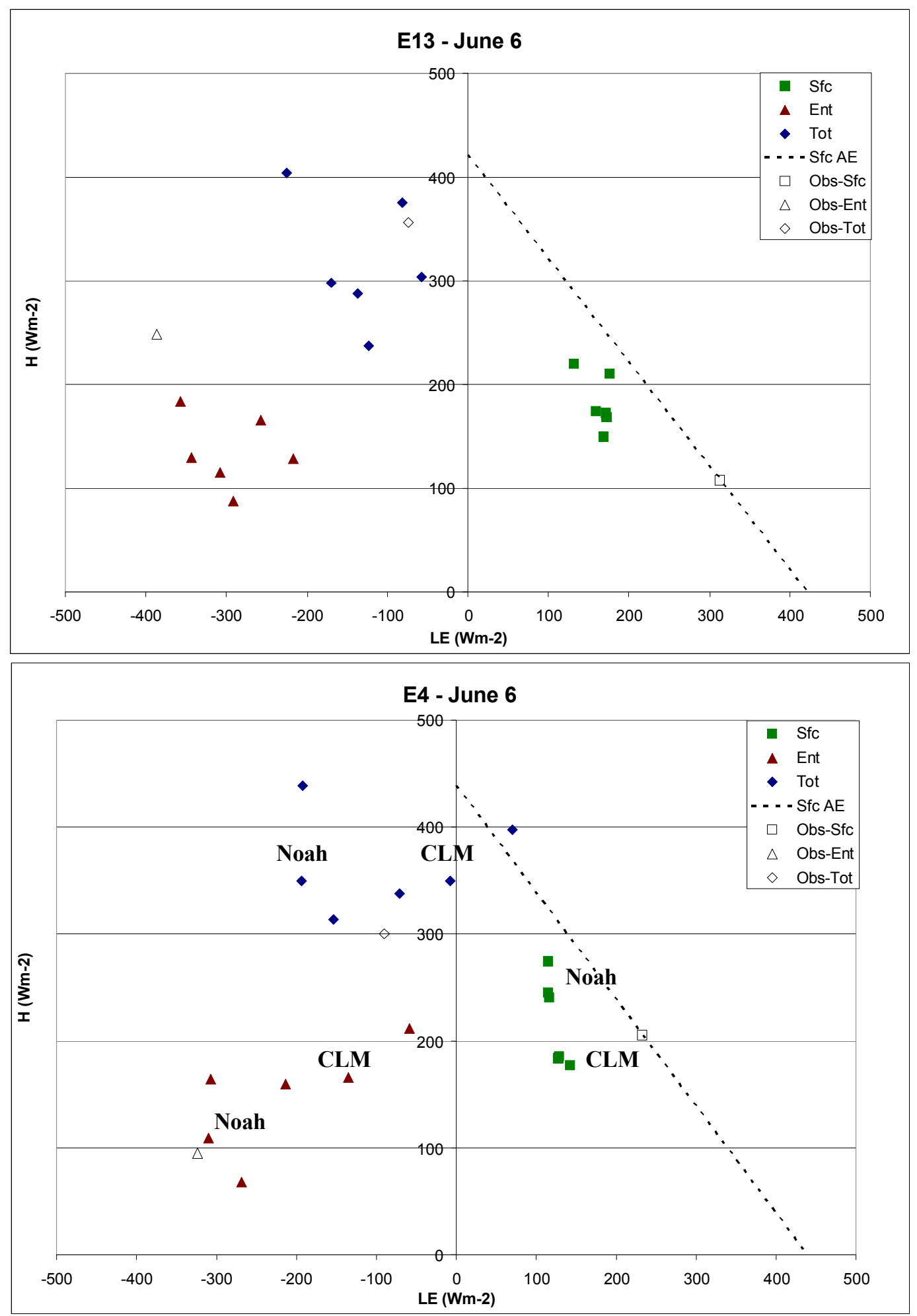

Figure 10: Same as Fig. 6, but for the a) E13 and b) E4 sites on 6 June 2002 (Figs. 8 and 9) along with observations (open black). The dashed line represents values of constant available energy $\left(H_{s f c}+L E_{s f c}\right)$ equal to that observed. 

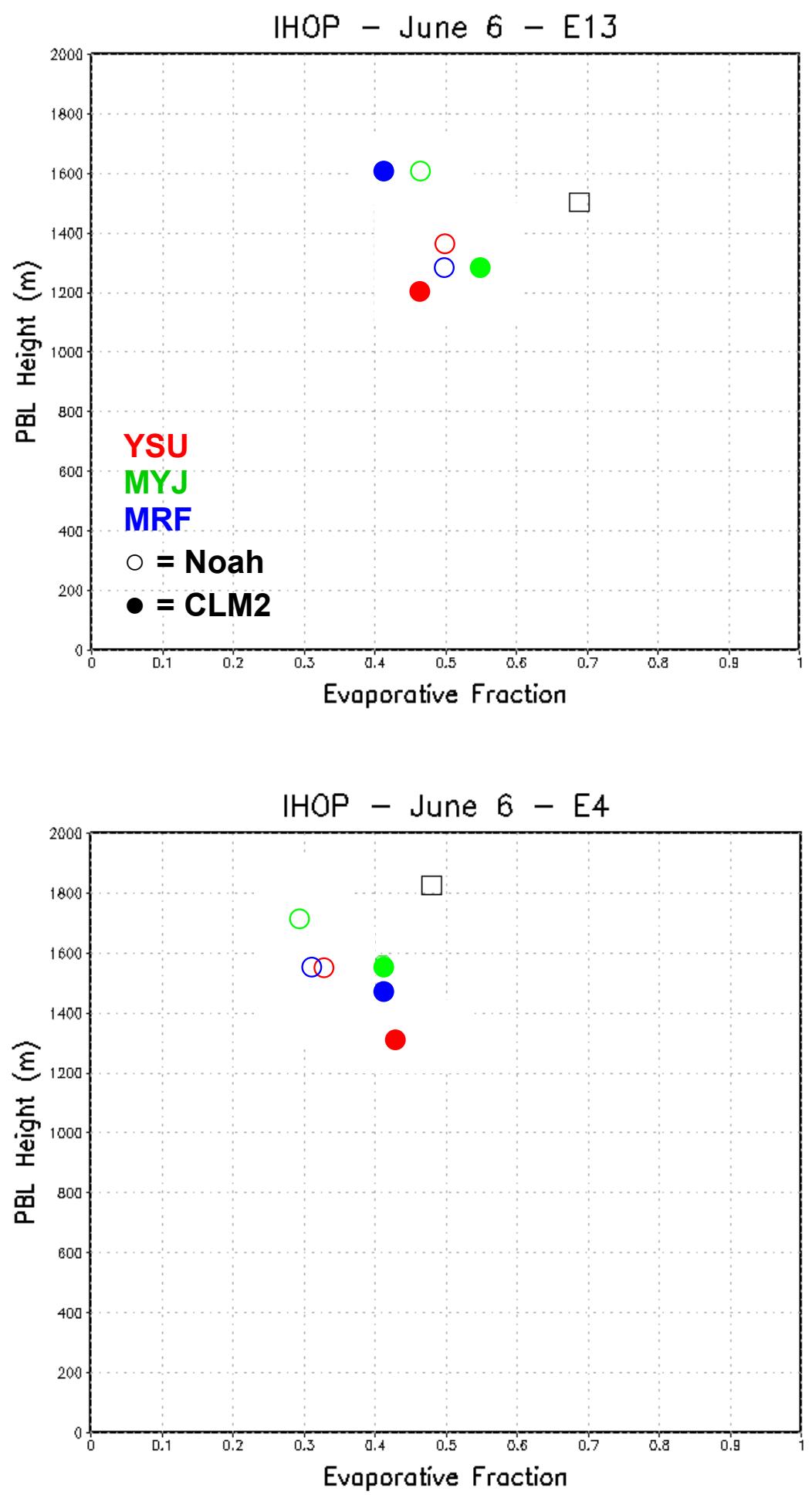

GRADS: COLA/GGES

Figure 11: Relationship of evaporative fraction $\left(L E_{s f c} /\left(L E_{s f c}+H_{s f c}\right)\right)$ to maximum PBL height as simulated by the Noah ( $\circ$ ) and CLM (•) LSMs coupled with the YSU (red), MYJ (green), and MRF (blue) PBL schemes in LIS-WRF on June 6 at the E13 and E4 sites shown in Figs. 8 and 9. 


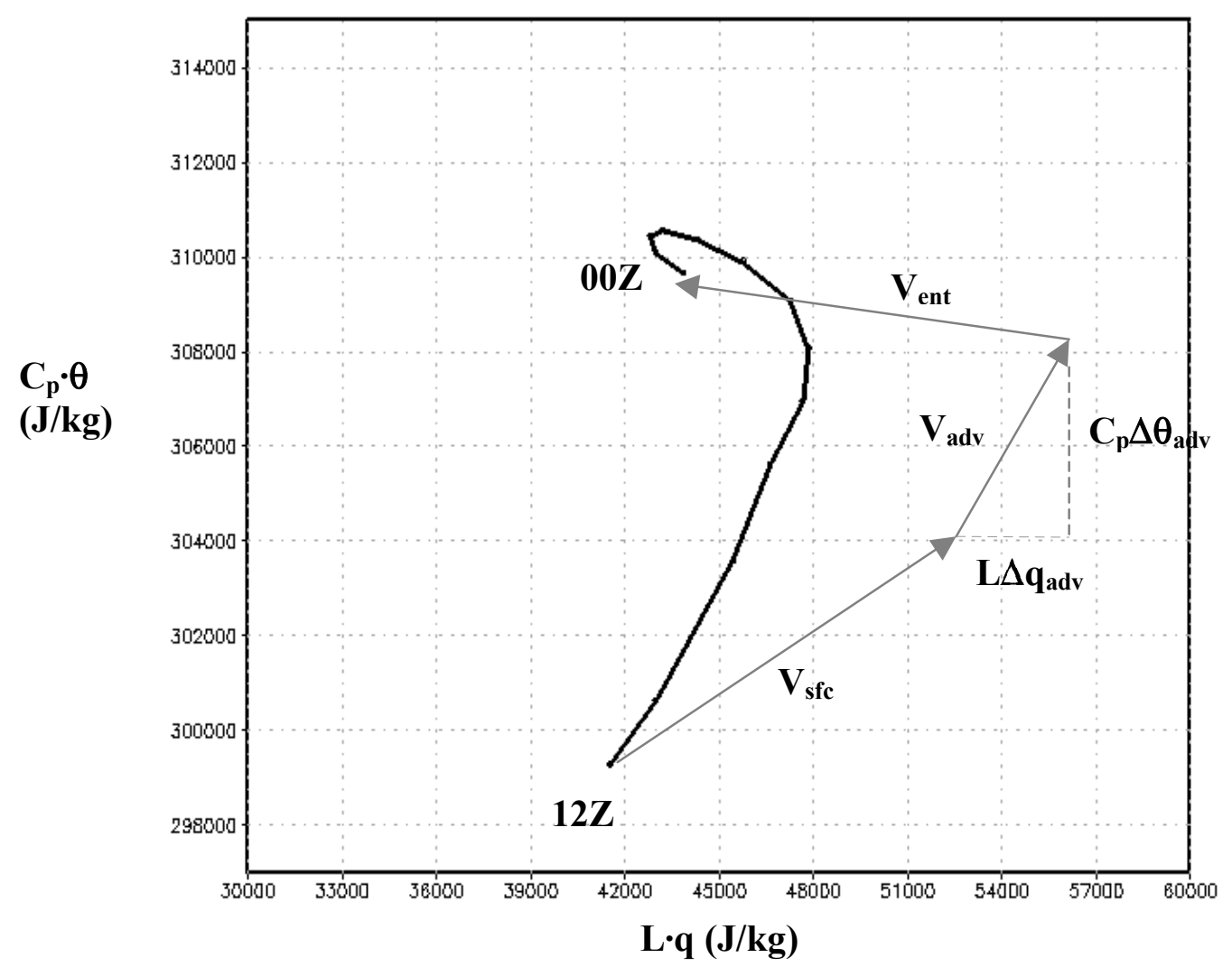

Figure 12: Diurnal evolution (12-00Z; solid line) of $2 \mathrm{~m}$-potential temperature $\left(C_{p} \theta\right)$ vs. $2 \mathrm{~m}$ specific humidity $(L q)$ from a representative day during June 2002 in the U.S. Southern Great Plains. The annotations on the plots depict the vector component contributions of surface and entrainment fluxes, and the addition of a vector due to the horizontal advection of heat and moisture $\left(\mathbf{V}_{\text {adv }}\right)$. 

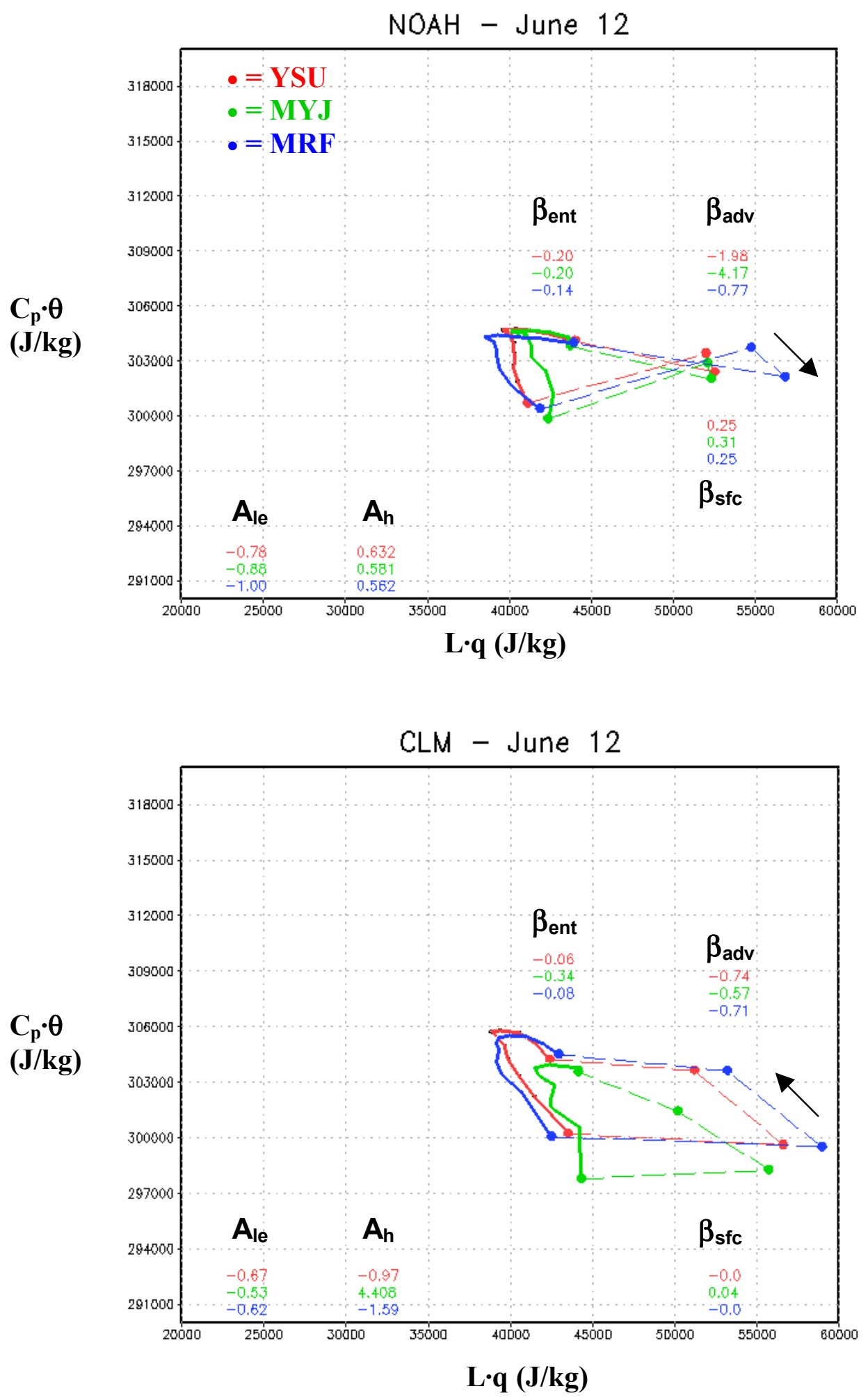

Figure 13: Mixing diagrams generated from LIS-WRF simulations using Noah and CLM for wet soil moisture conditions (see Fig. 5) with the addition of the horizontal advection vector $\left(\mathbf{V}_{\text {adv }}\right)$ and Bowen ratio $\left(\beta_{a d v}\right)$. The arrows indicate the direction of the advective fluxes. 
a)

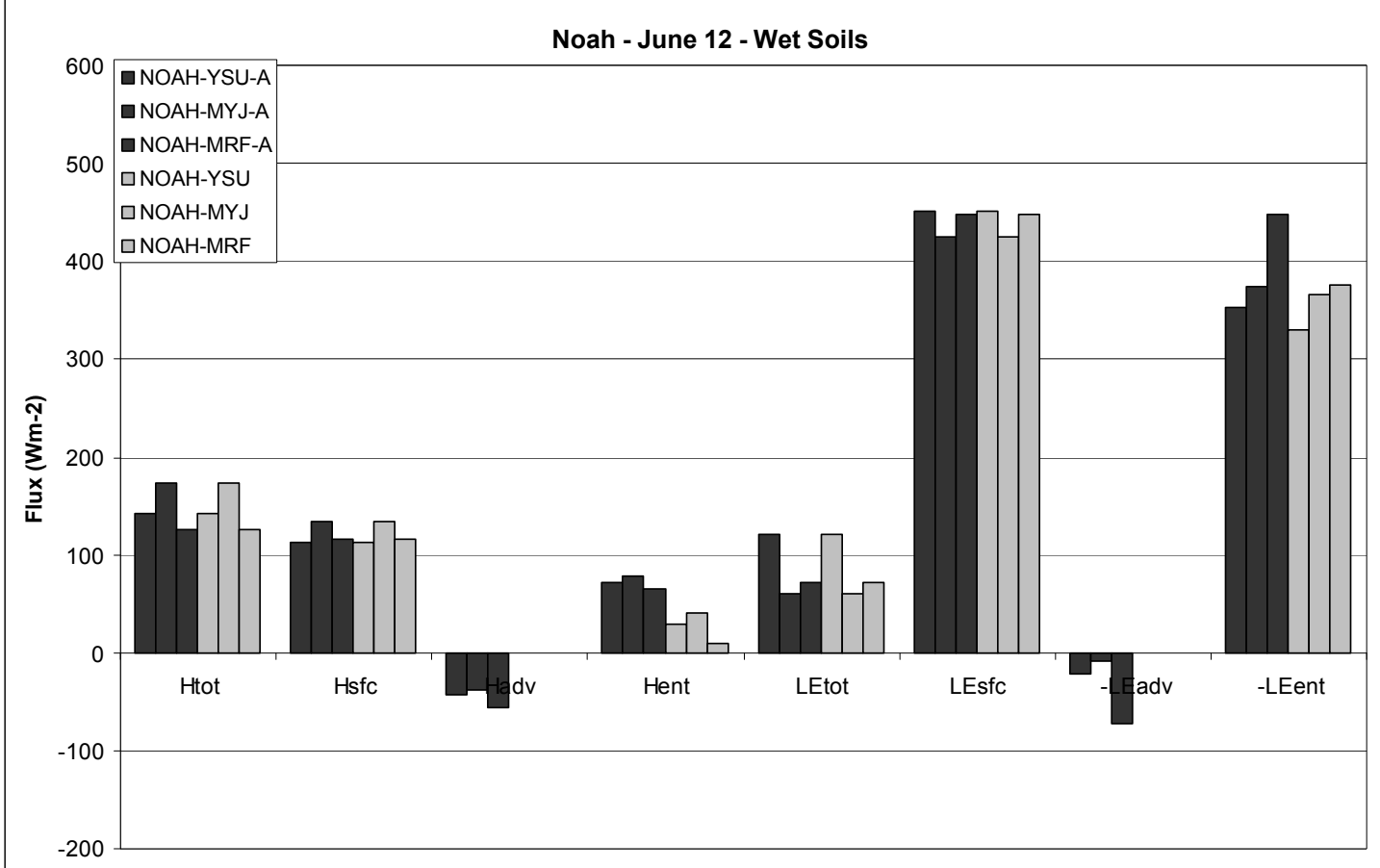

b)

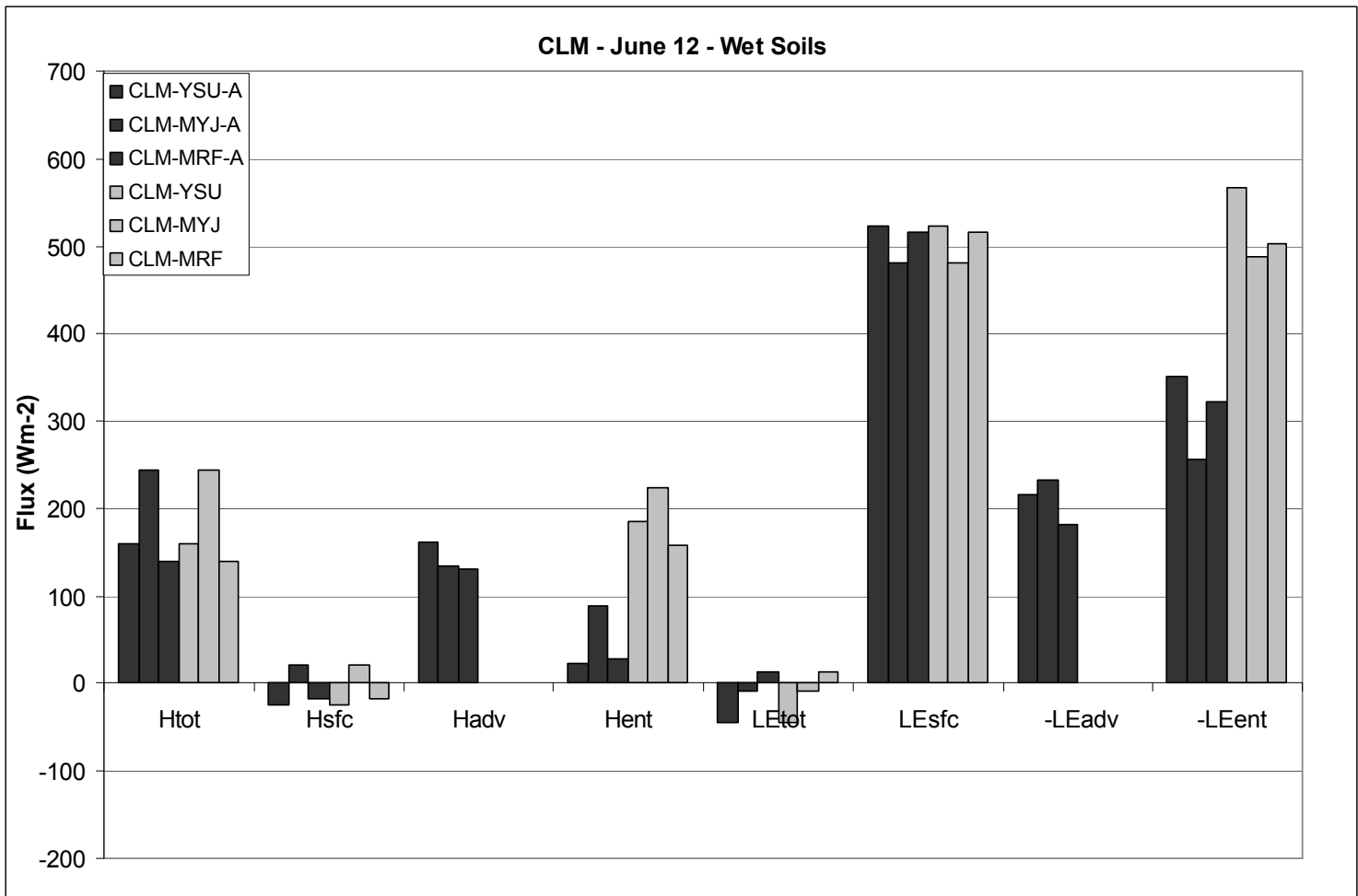


c)

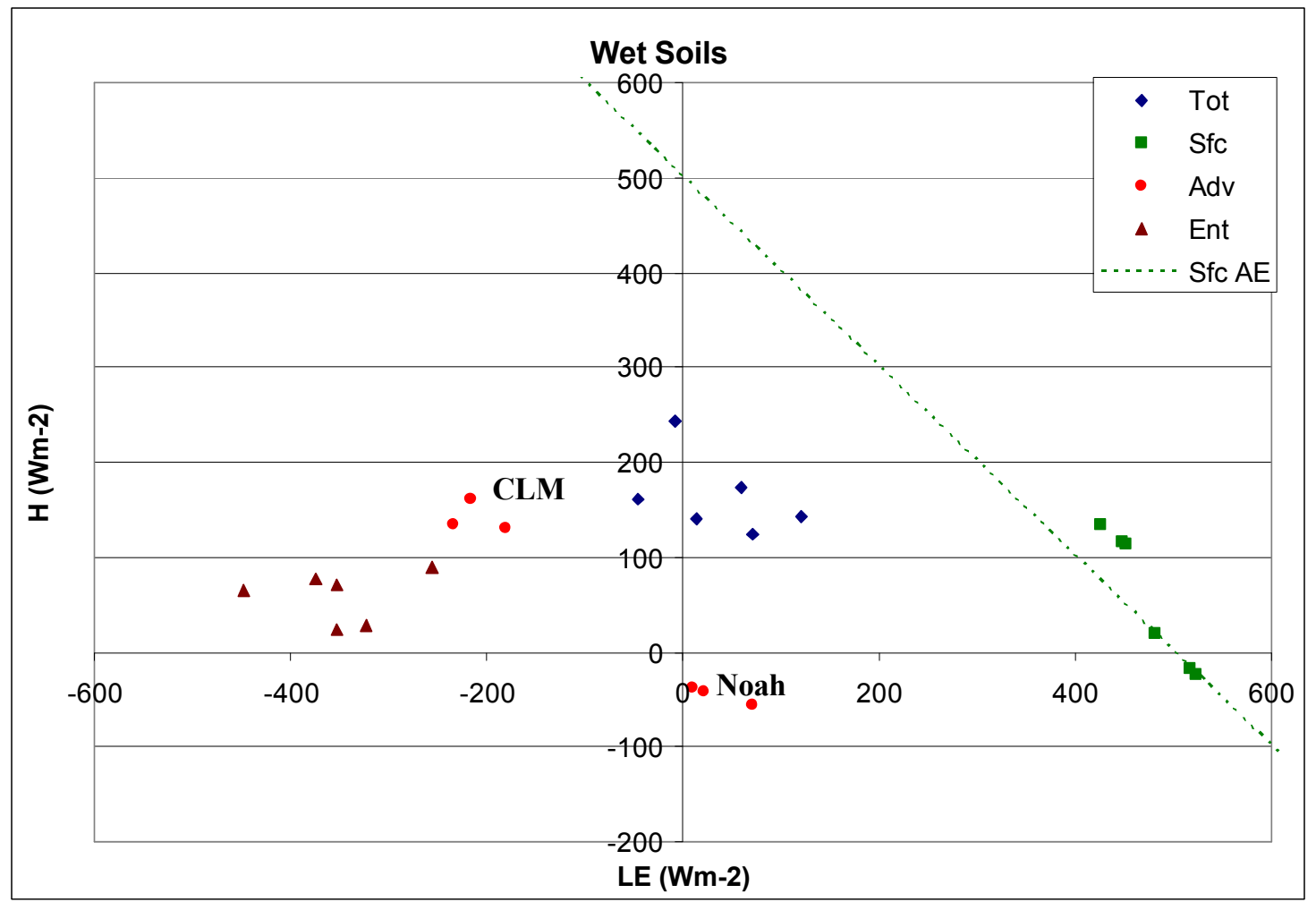

Figure 14: Total mean fluxes of heat $\left(H_{t o t}\right)$ and moisture $\left(L E_{t o t}\right)$ and their component fluxes from the land surface $\left(H_{s f c}, L E_{s f c}\right)$, advection $\left(H_{a d v}, L E_{a d v}\right)$, and entrainment $\left(H_{\text {ent }}, L E_{\text {ent }}\right)$ derived from the a) Noah and b) CLM mixing diagrams both without (from Fig. 5) and with (Fig. 13) advection, and c) plotted with advection as in Fig. 6c. 
Table 1: Mean fluxes of heat $\left(H_{t o t}\right)$ and moisture $\left(L E_{t o t}\right)$ and their component fluxes from the land surface $\left(H_{s f c}, L E_{s f c}\right)$ and entrainment $\left(H_{e n t}, L E_{e n t}\right)$ as simulated by LIS-WRF using the Noah and CLM LSMs with the YSU, MYJ, and MRF PBL schemes. The flux values (in $\mathrm{Wm}^{-2}$ ) were derived using the mixing diagram theory and surface and entrainment flux vectors for dry, intermediate, and wet soil conditions depicted in Figs. 3-5.

\begin{tabular}{|c|c|c|c|c|c|c|}
\hline DRY & $H_{\text {tot }}$ & $H_{s f c}$ & $H_{\text {ent }}$ & $L E_{t o t}$ & $L E_{s f c}$ & $L E_{\text {ent }}$ \\
\hline Noah-YSU & 1071.7 & 302.3 & 769.4 & -2428.2 & 96.2 & -2524.4 \\
\hline Noah-MYJ & 954.2 & 356.0 & 598.2 & -1664.1 & 94.7 & -1758.9 \\
\hline Noah-MRF & 854.2 & 303.6 & 550.6 & -1659.1 & 96.6 & -1755.7 \\
\hline CLM-YSU & 1517.3 & 347.7 & 1169.6 & -2607.0 & 41.8 & -2648.8 \\
\hline CLM-MYJ & 1059.7 & 346.5 & 713.2 & -1381.5 & 39.0 & -1420.5 \\
\hline CLM-MRF & 1476.7 & 339.1 & 1137.6 & -2281.5 & 41.3 & -2322.7 \\
\hline INT & $\boldsymbol{H}_{\text {tot }}$ & $\boldsymbol{H}_{\mathrm{s} f \mathrm{c}}$ & $H_{\text {ent }}$ & $L E_{\text {tot }}$ & $L E_{s f c}$ & $L E_{\text {ent }}$ \\
\hline Noah-YSU & 311.7 & 309.3 & 2.4 & -115.2 & 114.2 & -229.4 \\
\hline Noah-MYJ & 374.0 & 343.4 & 30.6 & -119.0 & 110.8 & -229.8 \\
\hline Noah-MRF & 270.3 & 311.3 & -40.9 & -100.1 & 113.3 & -213.4 \\
\hline CLM-YSU & 330.2 & 281.2 & 48.9 & -120.2 & 34.9 & -155.1 \\
\hline CLM-MYJ & 433.2 & 287.9 & 145.4 & -118.8 & 34.1 & -152.9 \\
\hline CLM-MRF & 338.0 & 283.8 & 54.2 & -117.9 & 34.6 & -152.6 \\
\hline WET & $H_{\text {tot }}$ & $\boldsymbol{H}_{s f c}$ & $H_{\text {ent }}$ & $L E_{\text {tot }}$ & $L E_{s f c}$ & $L E_{\text {ent }}$ \\
\hline Noah-YSU & 141.8 & 113.2 & 28.6 & 120.2 & 450.8 & -330.6 \\
\hline Noah-MYJ & 173.6 & 133.5 & 40.1 & 59.5 & 425.2 & -365.7 \\
\hline Noah-MRF & 125.1 & 115.8 & 9.4 & 71.4 & 447.7 & -376.2 \\
\hline CLM-YSU & 160.1 & -24.2 & 184.3 & -45.0 & 522.6 & -567.6 \\
\hline CLM-MYJ & 243.2 & 20.2 & 222.9 & -7.9 & 481.0 & -488.9 \\
\hline CLM-MRF & 140.0 & -17.6 & 157.6 & 13.7 & 516.5 & -502.8 \\
\hline
\end{tabular}

